\begin{tabular}{|c|c|c|}
\hline Beitr. Ent. & Keltern & ISSN 0005-805X \\
\hline $\mathbf{6 2}(2012) 1$ & S. $165-206$ & 15.05 .2012 \\
\hline
\end{tabular}

\title{
Beitrag zur Kenntnis der Tineiden von Nepal und benachbarter Gebiete
}

\section{(Lepidoptera: Tineidae)}

Mit 109 Figuren

Reinhard Gaedike

\section{Zusammenfassung}

Die bisher undeterminierten Tineidae der Nepal-Expeditionen der Zoologischen Staatssammlung München wurden bearbeitet, zusammen mit Aufsammlungen aus den Museen Paris, Helsinki, Kopenhagen, und aus den Sammlungen Georg Derra und Ernst Arenberger einige Falter aus Indien und Pakistan. Als neue Arten werden beschrieben: Rhodobates dierli sp. n.; R. pusillus sp. n.; Infurcitinea fibigeri sp. n.; Pachyarthra nepalica sp. n.; . dierli sp. n.; P. aurata sp. n.; Edosa aculeata sp. n.; E. parva sp. n.; E. magna sp. n.; E. fastigata sp. n.; E. rapticola sp. n.; E. clavifera sp. n.; E. dierli sp. n.; E. hackeri sp. n.; E. spinosa sp. n.; E. fibigeri sp. n.; Tinea nepalica sp. n.; Crypsithyris arenbergerarum sp. n.; C. nepalicola sp. n.; C. cornuta sp. n. Von den drei Arten Edosa opsigona (Merrick, 1911), E. nestoria (MeYrick, 1910) und Perissomastix (Aphrodoxa) peterseni (AMSEL, 1959) wird erstmals das weibliche Genital abgebildet. Neufunde für Nepal sind: Edosa subochraceella (Walsingham, 1886); E. orphnodes (Meyrick, 1911); Perissomastix afghana (Petersen, 1959); Monopis longella (Walker, 1863) und Gerontha dracuncula MeYrick, 1928. Für Pakistan sind Edosa synaema (Meyrick, 1905) und Perissomastix afghana (Petersen, 1959) Neufunde, für Indien ist es Perissomastix (Aphrodoxa) peterseni (Amsel, 1959). Von den neuen Arten werden die Falter sowie die Genitalien abgebildet.

\section{Summary}

The hitherto undetermined Tineidae from the Nepal expeditions of the Zoologische Staatssammlung München were studied, together with material from the museums of Paris, Helsinki, Copenhagen, and some specimens from India and Pakistan from the collections of Georg Derra and Ernst Arenberger. The following new species are described: Rhodobates dierli sp. n.; R. pusillus sp. n.; Infurcitinea fibigeri sp. n.; Pachyarthra nepalica sp. n.; P. dierli sp. n.; P. aurata sp. n.; Edosa aculeata sp. n.; E. parva sp. n.; E. magna sp. n.; E. fastigata sp. n.; E. rapticola sp. n.; E. clavifera sp. n.; E. dierli sp. n.; E. hackeri sp. n.; E. spinosa sp. n.; E. fibigeri sp. n.; Tinea nepalica sp. n.; Crypsithyris arenbergerarum sp. n.; C. nepalicola sp. n.; C. cornuta sp. n. Female genitalia of the following three species are described for the first time: Edosa opsigona (MeYrick, 1911), E. nestoria (Meyrick, 1910), and Perissomastix (Aphrodoxa) peterseni (Amsel, 1959). Edosa subochraceella (Walsingham, 1886); E. orphnodes (Meyrick, 1911); Perissomastix afghana (Petersen, 1959); Monopis longella (WALKer, 1863), and Gerontha dracuncula Meyrick, 1928 are recorded as new for the fauna of Nepal, Edosa synaema (Meyrick, 1905) and Perissomastix afghana (Petersen, 1959) for Pakistan, and Perissomastix (Aphrodoxa) peterseni (AMSEL, 1959) for India. Adults and genitalia of all new species are figured.

\section{Vorbemerkungen}

Nachdem Petersen (1982) die Tineiden bearbeiten konnte, die während der 1962 (Ebert \& FALKNER) und 1964 (DierL) durchgeführten Nepal-Expeditionen erbeutet wurden, hatte ich die 
Möglichkeit, neben einigen Nachträgen von 1964 die Ausbeute dieser Familie zu untersuchen, die 1967 für die ZSM zusammengetragen wurde (leg. Dierl; Forster; Schacht). Zusätzliches Material erhielt ich aus dem Pariser Museum (leg. Minet \& Orousset), dem Museum Helsinki (leg. Mikкola \& Wikberg), dem Museum Kopenhagen (leg. Fibiger) sowie aus der Sammlung Derra (leg. Hacker \& PeKs). Es wurden außerdem noch einige Exemplare aus Nachbargebieten mit in die Untersuchung einbezogen (leg. Ernst \& Margarete Arenberger).

Über die Mikrolepidopterenfauna von Nepal erschien 1995 (RoBInson et al.) eine Checkliste, in der 31 Arten aufgeführt sind. Zusätzlich mit aufgeführt sind 21 nur bis zur Gattung determinierte Taxa (9 Edosa sp.; 4 Eudarcia sp.; 1 Gerontha sp.; 6 Opogona sp.; 1 Platyspectra sp.), sowie weitere 4 ungekannte Taxa. Leider war es nicht möglich, die o. g. Edosa-Arten in die Untersuchung mit einzubeziehen, da die Exemplare in den Sammlungen des Britischen Museums London nach Auskunft von K. R. Tuck nicht auffindbar waren. Die anderen Gattungen waren im untersuchten Material (Ausnahme Gerontha) nicht vertreten.

Nachfolgend werden alle im Nepal-Material nachgewiesenen Taxa aufgeführt, die bis zur Art determiniert werden konnten. Eine Anzahl von Faltern kann gegenwärtig nicht eindeutig identifiziert werden. Die große Anzahl neuer Taxa zeigt, wie unvollkommen derzeit unsere Kenntnis der Fauna von Nepal noch ist.

\section{Rhodobates dierli sp. n. (Fig. 1; 24-27)}

Typus. Holotypus: ơ , Nepal, Helmu-Gebiet, Gusum Banjyang, 2600 m, 3.ix.1967, leg. W. Dierl, Gen. präp. R. Gaedike Nr. 4380; ZSM.

Beschreibung (Fig. 1):

Spannweite $14 \mathrm{~mm}$; Stirnschopf nur noch in Resten vorhanden, cremefarben, Antennen und Labialpalpen abgebrochen; Thorax hell graubraun, Tegulae dunkler; Vorderflügel dunkel graubräunlich, von der Basis schräg unterhalb der Zelle ein dunkler undeutlicher Streifen bis zum Dorsum bei $1 / 3$, dort in einem dunkelbraunen Fleck mündend, dieser reicht schräg nach oben bis zum Ende der Zelle; die Fläche unterhalb des Streifens heller braun; Hinterflügel grau.

${ }^{\star}$ Genital (Fig. 24-27): Uncus in der Mitte eingesenkt, die beiden Socii mit je zwei spitzen, stark sklerotisierten Zähnen; Gnathosarme schmal, gebogen, apikal stark sklerotisiert, mit je zwei kurzen Zähnen; Tegumen ventral schmal, ohne Saccus; Valve so lang wie Uncus-Tegumen, basal am breitesten, allmählich zur verrundeten Spitze schmaler werdend, Transtilla kurz, Anellus durch eine stärker sklerotisierte Spange mit der Valve verbunden; Phallus kürzer als die Valve, gerade, bei 2/3 etwas eingeschnürt, letztes Drittel etwas stärker sklerotisiert als der übrige Phallus.

† Genital: Unbekannt.

Etymologie: Benannt nach Herrn Dr. Wolfgang Dierl, der mir die Untersuchung der NepalAusbeute ermöglichte.

\section{Bemerkung:}

Der gerade und kurze Phallus unterscheidet die neue Art deutlich von den anderen aus der Region bekannten Arten, Uncus und Gnathosarme ähneln dem aus China beschriebenen $R$. cupulatus Li $\&$ XIAO, 2006, diese Art besitzt aber ein breites, mehr oder weniger dreieckiges Tegumen. 
Rhodobates pusillus sp. n. (Fig. 2-3; 28-31)

Typen. Holotypus ơ, S Nepal, Makwampur distr., $35 \mathrm{~km}$ W Hetaura, $300 \mathrm{~m}$, mixed sal. For., 22.ii.1995, K. Mikkola \& A. Wikberg leg.; - Paratypen: $20^{*}, 1$ \% , mit den gleichen Angaben; 1 ơ, 1 ㅇ, Nepal, Kathmandu, Phulchoki Mt. 26.ii.1995, 1700 m, K. Mikkola \& A. Wikberg leg.; 1 , Nepal, 30 km E Kathmandu, 900 m, young mixed sal for., 1.iii.1995, leg. K. Mikkola; 1 ․ Nepal, 15 km SW Kathmandu Hattiban, pine for. 1500 m, 2.iii.1995, leg. K. Mikkola \& A. Wikberg; 1 ơ $^{\star}$ Nepal, Centr. N, Mailung Khola, 1050 m, 24.x.1995, leg. M. Fibiger.

Der Holotypus und 4 Paratypen im FMNH, 3 Paratypen im SDEI, 1 Paratypus im ZMUC.

Beschreibung (Fig. 2-3):

Spannweite 10-15 mm; Stirnschopf hell strohgelb, oberhalb der Palpen fast weiß, seitlich über den Augen einige dunkle Schuppen; Antenne dunkelbraun; die ersten beiden Glieder der Labialpalpen außen braun, innen weißlich, zweites Glied mit einigen Borsten, letztes Glied komplett weißlich; Thorax und Tegulae dunkelbraun; Vorderflügel fast einfarbig dunkelbraun, nur ein schmaler Rand entlang des Dorsum manchmal heller braungelblich, bei insgesamt helleren Exemplaren (Fig. 3) ist die apikale Flügelhälfte heller, an der Costa mit mehreren kurzen dunklen Streifen; Hinterflügel grau.

$\sigma^{\top}$ Genital (Fig. 28-30): Uncus gerade abgeschnitten, ohne Socii; Ganthosarme lang und schmal, am Ende kugelförmig, stärker sklerotisiert, Tegumen schmal, ohne Saccus; Valve so lang wie Uncus-Tegumen, breit, Costalrand fast gerade, Ventralrand bei 1/3 etwas eingesenkt, im letzten Drittel gleichmäßig schmaler werdend, Apex rund; Phallus so lang wie die Valve, dünn, vor der Spitze abgebogen.

† Genital (Fig. 31): Ventraläste der vorderen Apophysen kurz, in einer langgezogen dreieckigen Platte endend, Ostium und Anfangsteil des Ductus bursae mit fein granulierter Sklerotisierung.

Etymologie: Benannt wegen der gegenüber den anderen Vertretern der Gattung geringen Größe.

\section{Bemerkung:}

Das Fehlen von Socii und die Form der Gnathosarme macht die Art unverwechselbar gegenüber den bisher bekannten Vertretern der Gattung.

\section{Nemapogon asyntacta (MEYRICK, 1917)}

Verbreitung: Tibet, Kaschmir, Assam, Nepal.

Untersuchtes Material:

Nepal: 1 ơ $^{\star}$ Kathmandu, 1400 m, 30.v.1964, leg. W. Dierl, ZSM.

\section{Infurcitinea fibigeri sp. n. (Fig. 4; 32-34)}

Typen. Holotypus ơ , Nepal, Centr. N. Ganesh Himal, Nesim, 2200 m, 23.x.1995, leg. M. Fibiger; Gen. Präp. R. Gaedike Nr. 7403; - Paratypus: $10^{\star}$, Nepal, Centr. N, Ganesh Himal, Gholjong, 2420 m, 12.x.1995, leg. M. Fibiger.

Der Holotypus im ZMUC, der Paratypus im SDEI. 


\section{Beschreibung (Fig. 4):}

Spannweite $10 \mathrm{~mm}$; Stirnschopf hell cremefarben, fast weiß; Scapus oben dunkelgraubraun, unten fast weiß, Flagellum geringelt; Labialpalpen außen dunkelgraubraun, innen fast weiß, 2. Glied mit einigen Borsten; Thorax und Tegulae hell cremefarben, mit verstreuten dunklen Schuppen, auf den Tegulae gehäuft; Vorderflügel hell cremefarben, mit dunkler Schuppenzeichnung: dunkel sind der Costalrand von der Basis bis 1/4, ein mehr oder weniger dreieckiger Fleck bei 1/3 vom Costalrand bis zur Zelle, je ein Fleck am Ende der Zelle, vor dem Apex und am Beginn der Zelle. Der gesamte Flügel mit einzelnen dunklen Schuppen überdeckt, so dass die Grenzen der dunklen Flächen verschwommen erscheinen; Hinterflügel glänzend weiß.

$0^{\star}$ Genital (Fig. 32-34): Uncus sehr groß, hinter der Basis verbreitert, zum Apex schmaler werdend, abgeschnitten endend, mit gerundeten Ecken, die Seiten und der Apex in einem breiten Saum mit zahlreichen kleinen spitzen Stacheln besetzt; Tegumen schmal, Vinculum seitlich in zwei kurzen Spitzen auslaufend; Valve so lang wie Uncus-Tegumen, schmal, Costalrand leicht konvex, Ventralrand hinter 1/2 mit einer stumpfen Ausbuchtung, Transtilla in einer ringförmigen Sklerotisierung mit einem stumpfen Zahn auslaufend; Anellus länger als die Valve, mit schmaler Basis, apikal breiter werdend, Apex oval, mit zahlreichen spitzen Stacheln und einer Reihe kräftiger Dornen besetzt; Phallus klein, nur ein Drittel so lang wie der Anellus, basal breit, gleichmäßig zur Spitze hin schmaler werdend, fest mit dem Anellus verbunden.

† Genital: Unbekannt.

Etymologie: Benannt zu Ehren des leider so früh verstorbenen Noctuiden-Spezialisten MichaEL FIBIGER, der durch seine Aufsammlungen auch für die Mikrolepidopterologie zahlreiche unbekannte Taxa entdeckt hat.

\section{Bemerkung:}

Die neue Art steht der aus Afghanistan beschriebenen I. safedella Petersen, 1973 nahe, sie ist aber anhand der Genitalstrukturen eindeutig zu unterscheiden. Der neuen Art fehlt die Lamelle am Valvenende sowie der basale dreieckige Fortsatz von safedella, das ovale Ende des Anellus sowie der deutlich größere Phallus sind weitere Unterschiede.

Pachyarthra nepalica sp. n. (Fig. 5-6; 35-38)

Typen. Holotypus: ơ, Nepal, Chitwan: Sauraha, UV, 27.v.1986, alt. 190 m, appr. $27^{\circ} 34^{\prime} \mathrm{N}$, $84^{\circ} 29^{\prime}$ E, leg. J. Minet \& J. Orousset, Gen. präp. R. Gaedike Nr. 4364. - Paratypen: $10^{\star}$, vom gleichen Fundort, aber: chenille 22./23.v.1986, e.l. 28.vi.1986; 3 ㅇ, Nepal, env. de Kathmandu: Nagarjun Ban, 4.vi.1986, alt. 1400 m, 2745'N, 85¹7'E, leg. J. Minet \& J. Orousset.

Der Holotypus und 2 Paratypen im MNHN, 2 Paratypen im SDEI.

Beschreibung (Fig. 5-6):

Spannweite $17 \mathrm{~mm}\left({ }^{\star}\right), 22-23 \mathrm{~mm}$ ( ( ); Stirnschopf, Antennen und Labialpalpen hell lehmbraun, die beiden ersten Glieder dicht und nach unten abstehend beschuppt, 2. Glied apikal beborstet, das 3. Glied kurz, schräg nach oben gerichtet; Thorax und Tegulae etwas dunkler als der Stirnschopf; Vorderflügel einfarbig dunkel lehmbraun; Hinterflügel etwas dunkler, Costalrand hell, beide Flügel bei Seitenlicht bläulich irisierend; Färbung der + dunkel lehmbraun, Vorderflügel dicht mit dunklen Schuppen überdeckt, Fransen dunkler als der übrige Flügel, Hinterflügel dunkelgraubraun. 
o Genital (Fig. 35-37): Uncus mit zwei langen Socii, apikal rechtwinklich endend, stark sklerotisiert, Gnathosarme in der Mitte abgewinkelt, stumpf eckig endend; Valve so lang wie UncusTegumen-Vinculum, Basis breit, Transtilla und Basalrand stärker sklerotisiert, Ventralrand breit umgeschlagen, apikales Viertel deutlich schmaler, Spitze rund; Phallus in der Mitte abgewinkelt, in zwei verrundeten Lappen endend.

† Genital (Fig. 38): Ovipositorklappen breit; vordere Apophysen ventral durch eine halbmondförmige Sklerotisierung, dorsal durch eine schmale bandförmige Sklerotisierung verbunden, Ostium mit einem Netz aus feinen Zähnchen umgeben.

Etymologie: Die Art ist nach dem Land der Typenfundorte benannt.

\section{Bemerkung:}

Die neue Art ähnelt der aus Afghanistan beschriebenen P. asiatica Petersen, 1959, eindeutig zu unterscheiden ist sie durch den Bau des Phallus mit den beiden apikalen Lappen, die bei $P$. asiatica fehlen. Von der nachfolgend beschriebenen $P$. dierli unterscheidet sie sich durch die etwas andere Form der Valve und sehr deutlich durch den Bau des Phallus, der bei $P$. dierli länger und schmaler ist, und in der Mitte zwei Zähne besitzt.

Pachyartbra dierli sp. n. (Fig. 7; 39-43)

Typen. Holotypus: đ ${ }^{\star}$, Nepal, Rapti Tal, Monahari Khola, Belwa, 350 m, 5.-12.v.1967, leg. DierlForster-Schacht. - Paratypen: $30^{\star}, 1$, vom gleichen Fundort; $30^{*}$, Nepal, Rapti Tal, Jhawani, 200 m, 14.-19.v.1967, leg. Dierl-Forster-Schacht; 1 \% , vom gleichen Fundort, aber 15.v.1967.

Der Holotypus und 5 Paratypen in der ZSM, 3 Paratypen im SDEI.

Beschreibung (Fig. 7):

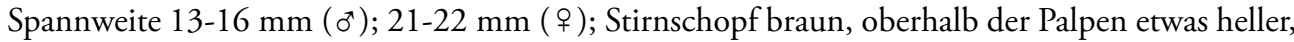
Scapus hell, Flagellum dunkel; Labialpalpen hell lehmfarben, die ersten beiden Glieder dicht abstehend beschuppt, 2. Glied apikal beborstet, 3. Glied kurz, schräg aufgerichtet; Thorax und Tegulae braun, mit feinen helleren Schuppen überrieselt; Vorderflügel zeichnungslos braun; Hinterflügel etwas heller, Fransen mit dunkler Schuppenlinie.

o Genital (Fig. 39-42): Uncus mit zwei langen Socii, basal breit, zur stumpfen, stärker sklerotisierten Spitze schmaler werdend; Gnathosarme bei 1/2 rechtwinklich abgewinkelt, stumpf endend; Valve so lang wie Uncus-Tegumen-Vinculum, Basis breit, Valve vor der Mitte am breitesten, danach gleichmäßig zur verrundeten Spitze schmaler werdend, Costalrand im letzten Viertel leicht konvex; Ventralumschlag undeutlich, Transtilla gerandet; Phallus dünn, basal etwas breiter, sichelförmig gebogen, vor der Mitte lateral mit zwei schlanken spitzen Zähnen, je nach Einbettung etwas unterschiedlich aussehend (Fig. 41-42).

† Genital (Fig. 43): Ovipositorklappen breit rechteckig, hintere Apophysen ventral durch eine bogenförmige, gerandete Sklerotisierung, dorsal durch eine bandförmige schmale Sklerotisierung verbunden; Ostium mit einem Netz aus sehr feinen Zähnchen umgeben.

Etymologie: Benannt nach Herrn Dr. Wolfgang Dierl, der mir die Bearbeitung des NepalMaterials der ZSM ermöglicht hat. 


\section{Bemerkung:}

Äußerlich unterscheidet sich die neue Art durch die dunklere Färbung von $P$. nepalica, deutliche Unterschiede im männlichen Genitalapparat sind die andere Form der Valve sowie der Besitz von Zähnen am Phallus, im weiblichen Genitalapparat ist die ventrale Sklerotisierung anders geformt.

Pachyarthra aurata sp. n. (Fig. 8; 44-47)

Typen. Holotypus: ${ }^{*}$, Nepal, env. de Kathmandu, Nagarjun Ban, 4.vi.1986, alt. 1400 m, $27^{\circ} 45^{\prime} \mathrm{N}, 85^{\circ} 17^{\prime} \mathrm{E}$, leg. J. Minet \& J. Orousset. - Paratypen: $60^{\star}$, vom gleichen Fundort.

Der Holotypus und 3 Paratypen im MNHN, 3 Paratypen im SDEI.

Beschreibung (Fig. 8):

Spannweite 14-16 mm; Stirnschopf, Antennen und Labialpalpen goldgelb, die beiden ersten Glieder der Palpen mit abstehenden Schuppen, 2. Glied apikal mit einigen Borsten; Thorax, Tegulae ebenfalls goldgelb, wie auch der Vorderflügel, dieser ohne Zeichnungsmuster, Costalrand in der basalen Hälfte dunkelbraun, apikale Hälfte mit einigen undeutlichen dunkleren kurzen Strichen vor dem Apex, Fransen dunkelbraun; Hinterflügel dunkelbraun.

$0^{\star}$ Genital (Fig. 44-47): Uncus mit zwei Socii, basal breit, mit stumpfer Spitze; Gnathosarme schlank, in der Mitte stark abgewinkelt, mehr oder weniger spitz endend; Valve so lang wie UncusTegumen-Vinculum, Basis breit, vor der Mitte stark eingeschnürt, ab da Costalrand convex, in einen beborsteten, spitz endenden Fortsatz ausgezogen, Ventralrand nur leicht konvex, kürzer als der Costalrand, das Valvenende schnabelförmig; Transtilla gerandet; Phallus deutlich kürzer als die Valve, leicht gebogen, von der breiten Basis bis zum spitz endenden Apex allmählich schmaler werdend, bei $2 / 3$ mit einem Feld kleiner Zähnchen, die Form sieht präparationsbedingt variabel aus (siehe Fig. 46-47).

† Genital: Unbekannt.

Etymologie: Benannt wegen der goldgelben Färbung.

\section{Bemerkung:}

Die Färbung unterscheidet die neue Art von den bisher bekannten Vertretern der Gattung. Im Genitalbau bestehen Ähnlichkeiten zu der aus dem Iran beschriebenen Pachyarthra brandti Petersen, 1966 (Uncus und Valve), der Phallus bei dieser Art besitzt aber im Gegensatz zu aurata eine mit ihm verbundene lange stabförmige Anellusbildung.

Edosa aculeata sp. n. (Fig. 9; 48-52)

Typen. Holotypus: ${ }^{\star}$, Nepal, Rapti Tal, Jhawani, 200 m, 14.-19.v.1967, leg. Dierl-ForsterSchacht. - Paratypen: $10^{\star}, 5$ + , mit den gleichen Daten; $20^{\star}, 7$ \% Nepal, Rapti Tal, Monahari Khola, Belwa, 350 m, 5.-12.v.1967, Dierl-Forster-Schacht; 3 ๙ $^{\star} 5$ ㅇ, Nepal, Prov. Chisapani Garhi, Bhainse Dobhan, 730 m, 16.-20.vii.1967, leg. Dierl-Schacht; 1 o, S Nepal, Makwampur distr., $35 \mathrm{~km}$ W Hetaura, 300 m, 22.ii.1995, leg. K. Mikkola \& A. Wikberg; 1 ㅇ, Nepal, 30 km E Kathmandu, 900 m, 1.iii.1995, leg. K. Mikkola.

Der Holotypus und 16 Paratypen in der ZSM, 6 Paratypen im SDEI, 2 Paratypen im FMNH. 


\section{Beschreibung (Fig. 9):}

Spannweite 16-18 mm (o); 16-23 mm ()); Stirnschopf hellgelb; Scapus ebenfalls hellgelb, Pedicellus dunkel; Labialpalpen kurz, außen braun, innen lehmfarben, 2. Glied mit Borsten; Thorax, Tegulae und Vorderflügel lehmfarben, ohne Flügelzeichnung, Fransen außen mit dunkler Schuppenlinie; Hinterflügel braun; die Weibchen insgesamt etwas dunkler gefärbt.

$0^{\top}$ Genital (Fig. 48-50): Uncus mit vier Socii, zwei nach oben gerichtet, Innenseite unterhalb des gerundeten Apex dicht bestachelt, zwei nach ventral gerichtet, schmal, die gerundeten Spitzen stärker sklerotisiert; Valve so groß wie Uncus-Tegumen-Vinculum, schaufelförmig, Costalrand konvex, Ventralrand halbrund erweitert, mit breit gerundetem Apex; Basalteil unterhalb der schmalen spitzen Transtilla gerandet, Phallus so lang wie die Valve, basal mit zwei kurzen Fortsätzen, im letzten Drittel verengt bis zur Spitze, fest verbunden mit einem breit ringförmigen Anellus, dieser mit der Innenseite des Vinculum verbunden.

† Genital (Fig. 51-52): Ventraläste der hinteren Apophysen enden in eine bandförmigen Fläche, die das Ostium umschließt, die Ränder beborstet, seitlich ein Bereich mit sehr kleinen Dornen; im Ductus bursae ein schmaler sklerotisierter Ring, Corpus bursae mit einer Längsreihe kleiner runder Signa.

Etymologie: Benannt nach der Bestachelung der Socii (lat. "aculeatus": "stachlig”).

\section{Bemerkung:}

Die neue Art ist durch die vier Socii und die Form der Valve eindeutig charakterisiert, unter den bisher bekannten Weibchen dieser Gattung ist die Signabildung ebenfalls einmalig.

Edosa parva sp. n. (Fig. 10-11; 53-58)

Typen. Holotypus: đo, Nepal, Rapti Tal, Jhawani, 200 m, 14.-19.v.1967, leg. Dierl-ForsterSchacht, Gen. präp. R. Gaedike Nr. 4361. - Paratypen: 4 9 , mit den gleichen Daten.

Der Holotypus und 3 Paratypen in der ZSM, 1 Paratypus im SDEI.

Beschreibung (Fig. 10-11):

Spannweite 10-13 mm; Stirnschopf gelbbraun, Antennen fast so lang wie die Vorderflügel, Scapus mit Pecten aus mehreren Borsten; Labialpalpen dunkler braun, 2. Glied mit mehreren Borsten; Thorax, Tegulae und Vorderflügel gelbbraun, glänzend; Costalrand nahe der Flügelbasis etwas dunkler, Fransen beim $\sigma^{\star}$ ebenfalls gelbbraun, beim + dunkelbraun; Hinterflügel dunkelgrau, Fransen mit dunkler Schuppenlinie.

${ }^{*}$ Genital (Fig. 53-56): Uncus mit zwei leicht geschwungenen, schlanken, spitz endenden Socii; Tegumen und Vinculum breit ringförmig, proximal gerandet; Valve kaum länger als die Socii, Transtilla rinnenförmig, stärker sklerotisiert, wie auch die Basis der Valve, Valvenkörper bauchig, apikal in zwei verrundeten, gleich langen Spitzen endend, an der Basis mit einem langen, spitz endenden Costalarm, dieser basal mit kurzen Dornen besetzt, die Form leicht asymmetrisch (siehe Fig. 55-56); Phallus so lang wie die Valve, mit breiter Basis, allmählich zur Spitze hin schmaler werdend, subapikal mit kleinen Zähnchen besetzt.

† Genital (Fig. 57-58): Ventralarme der vorderen Apophysen in einer sklerotisierten breiten Spange endend, lateral bestachelt, Dorsalarme durch eine bestachelte Fläche verbunden; Ostium mit sklerotisierten Kanten; am Ende des Ductus bursae eine längliche Sklerotisierung, apikal fein 
bedornt, in der Mitte etwas eingekerbt, zwei verrundete kurze Spitzen bildend, sie ragt in einen sklerotisierten Ring am Anfangsteil des Corpus bursae hinein.

Etymologie: Der Name (lat. "parvus" - "klein”) bezieht sich auf die geringere Größe des Genitalapparates im Bezug auf die nachfolgend beschriebene Art.

\section{Bemerkung:}

Die langen Socii sowie die Form der Valven mit der leichten Asymmetrie machen die neue Art gegenüber den bisher bekannten Vertretern der Gattung kenntlich.

Edosa magna sp. n. (Fig. 12; 59-63)

Typen. Holotypus: ${ }^{\star}$, Nepal, Prov. Chisapani Garhi, ChisapaniGarh, 1600 m, 11.-15. vii.1967, leg. Dierl-Schacht, Gen. präp. R. Gaedike Nr. 4399. - Paratypen: 1 \% , mit den gleichen Daten; $20^{*}$, Nepal, Prov. Chisapani Garhi, Bhainse Dobhan, 730 m, 16.-20.vii.1967, leg. Dierl-Schacht; $1 \sigma^{*}, 1$ ㅇ, Nepal, Kathmandu Valley, Godavari, 1600-1800 m, 1.-3.viii.1967, leg. Dierl-Schacht; - 2 o $^{\star}$, S Nepal, Makwampur distr., 35 km W Hetaura, 300 m, 22.ii.1995, leg. K. Mikkola \& A. Wikberg; FMNH; - 1 o $^{\star}$, Nepal, Centr. N, Mailung Khola, 1050 m,

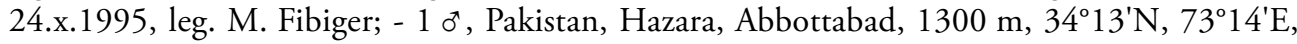
23./24.ix.1988, leg. Hacker.

Der Holotypus und 3 Paratypen in der ZSM, 2 Paratypen im SDEI, 2 Paratypen im FMNH, 1 Paratypus im ZMUC, 1 Paratypus in coll. Derra.

Beschreibung (Fig. 12):

Spannweite 10-15 mm; Stirnschopf hell gelbbraun, Antennen fast so lang wie die Vorderflügel; Scapus ohne Pecten; Labialpalpen außen dunkler als innen, 2. Glied mit zwei Borsten; Thorax und Tegulae dunkelbraun, Vorderflügel braun, glänzend, die + mit dunkleren Schuppenspitzen im Apexbereich; Hinterflügel graubraun.

$0^{\star}$ Genital (Fig. 59-62): Uncus mit zwei leicht geschwungenen, spitz endenden Socii, Tegumen und Vinculum breit ringförmig, lateral verbreitert; Valven fast so lang wie Uncus-TegumenVinculum, an der Basis mit komplizierter Sklerotisierung, Transtilla kurz, Valvenkörper bauchig, in zwei Spitzen ausgezogen, die ventrale lang und schmal, die costale nur halb so lang, stumpf endend, Costalarm basal und fast auf der gesamten Innenseite mit kurzen Dornen besetzt, die Form asymmetrisch: rechts spitz endend, links verrrundet endend (siehe Fig. 60-61); Phallus so lang wie die Valve, mit breiter Basis, zur Spitze hin leicht geschwungen, gleichmäßig schmaler werdend, nur mit wenigen Zähnchen subapikal.

† Genital (Fig. 63): Im Unterschied zu voriger Art ist die längliche Sklerotisierung am Ende des Ductus bursae apikal tief eingeschnitten, sie bildet zwei bedornte verrundete Spitzen.

Etymologie: Der Name (lat.: “magnus” - "groß”) bezieht sich auf die Größe des Genitalapparates im Vergleich zu E. parva.

\section{Bemerkung:}

Die Form der Valven mit den unterschiedlich langen Spitzen sowie die Form der Costalarme unterscheidet die neue Art, neben der Größe des Gesamtapparates, von E. parva. 
Edosa fastigata sp. n. (Fig. 13; 64-67)

Typen. Holotypus: $0^{\star}$, Pakistan, Hazara Manshera, $15 \mathrm{~km}$ n. Taxilla; $600 \mathrm{~m}, 33^{\circ} 53^{\prime} \mathrm{N}, 72^{\circ} 56^{\prime} \mathrm{O}$, 14.x.1988, leg. H. Hacker, Gen. präp. R. Gaedike Nr. 4375. - Paratypen: $20^{\star}$, Pakistan, Salt Range, 4 km nw Choa Saidan, 800 m, 32 46' N, 7303'E, 10.x.1988, leg. H. Hacker; $10^{\star}$, Nepal, Rapti Tal, Monahari Khola, Belwa, 350 m, 5.-12.v.1967, leg. Dierl-Forster-Schacht.

Der Holotypus und ein Paratypus in coll. G. Derra, je ein Paratypus im SDEI und in der ZSM.

Beschreibung (Fig. 13):

Spannweite 13-15 mm; Stirnschopf hell gelbbraun, Antenne heller, Scapus mit Pecten aus wenigen Borsten; Labialpalpen außen dunkler, innen hell, 2. Glied apikal mit einigen Borsten; Thorax, Tegulae und Vorderflügel braun, glänzend, Costa and der Basis sowie Apex etwas dunkler; Hinterflügel braun.

o Genital (Fig. 64-67): Uncus mit zwei langen Socii, an der Basis breit oval, zur Spitze längs verdreht, Spitze abgeschrägt, stärker sklerotisiert, Tegumen und Vinculum einen breiten Ring bildend, lateral am breitesten, Valve so lang wie Uncus-Tegumen-Vinculum, Transtilla klein, spitz, Basis breit, an der Innenseite eine schalenförmige Sklerotisierung, Costalrand convex, hinter 1/2 mit einem lappenförmigen Fortsatz, von da an bis zum Apex spitz zulaufend; Phallus kürzer als die Valve, Basis trichterförmig, dahinter deutlich schmaler werdend, seitlich stärker sklerotisiert, Spitze stumpf, über die gesamte Länge leicht geschwungen (Lateralansicht, siehe Fig. 66).

† Genital (Fig. ): Unbekannt.

Etymologie: Der Name (lat.: "fastigatus" - "in eine Spitze auslaufend") bezieht sich auf die Form der Valve.

\section{Bemerkung:}

Die Socii mit der abgeschrägten Spitze sowie die Form der Valve kennzeichnet die neue Art und macht sie unterscheidbar gegenüber den anderen Vertretern der Gattung.

Edosa rapticola sp. n. (Fig. 14; 68-72)

Typen. Holotypus: ${ }^{\star}$, Nepal, Rapti Tal, Monahari Khola, Belwa, 350 m, 5.-12.v.1967, DierlForster-Schacht, Gen. Präp. R. Gaedike Nr. 4398. Paratypen: $10^{\star}, 3$, mit den gleichen Angaben. - 2 \% , Nepal, Prov. Chisapani Garhi, Chisapani garhi, 1600 m, 11.-15.vii.1967, leg. Dierl-Forster-Schacht. - 1 \% , Nepal, Kathmandu Valley, Godavari, 1600-1800 m, 1.-3.viii.1967, leg. Dierl-Schacht.

Der Holotypus und 4 Paratypen in der ZSM, 3 Paratypen im SDEI.

Beschreibung (Fig. 14):

Spannweite 11-14 mm; Stirnschopf der $0^{\star}$ weiß, Nacken und seitlich mit dunklen Schuppen, bei den + gelb; Antenne der $\sigma^{*}$ deutlich dicker als die der $\$$, Scapus mit Pecten; Labialpalpen außen dunkler braun als innen, 2. Glied mit einigen Bosten; Thorax braun, Tegulae an der Basis dunkler; Vorderflügel hell lehmfarben, Costa an der Basis dunkler, Fransen mit dunkler Schuppenlinie; Hinterflügel grau; Vorderflügel der + etwas dunkler, die Schuppen, gehäuft in der apikalen Hälfte, mit dunkler Spitze. 
đ Genital (Fig. 68-70): Uncus mit zwei dünnen, nach außen gebogenen Socii mit runder Spitze und breiter ovaler Basis; Tegumen und Vinculum einen breiten Ring bildend, apikaler Rand mit breiter stark sklerotisierter Kante; Valve sehr klein, doppelt so breit wie lang, Costalrand verrundet in den Außenrand übergehend, Ventralrand konvex, am Außenrand in einem Zahn endend; Phallus etwas länger als die Valvenbreite, mit dem Anellus an der Innenseite des Vinculum verbunden, in zwei Spitzen endend.

† Genital (Fig. 71-72): Die gegabelten Apophysen ventral durch eine breite Spange verbunden, Ostium an den Seiten mit kleinen Sklerotisierungen, am Ende des Ductus bursae die für viele Arten der Gattung charakteristische Sklerotisierung mit zwei bedornten Spitzen, die in den Ring am Anfang des Corpus bursae hineinreichen.

Etymologie: Die Art ist nach der Fundregion des Holotypus (Rapti Tal) benannt.

\section{Bemerkung:}

Von den bisher aus Nepal bekannten Arten durch die sehr kleine Valve und die Form des Phallus deutlich zu unterscheiden.

\section{Edosa subochraceella (WALSINGHAM, 1886) (Fig. 73-79)}

\section{Untersuchtes Material:}

Nepal: $20^{\star}$, env. Kathmandu valley, Nagarjun Ban, 1400 m, 19., 30.vii.1982, leg. J. Boudinot \& J. Minet; MNHN; 1 ơ, 1 \% , Rapti Tal, Jhawani, 200 m, 14.-19.v.1967, leg. Dierl-ForsterSchacht; ZSM; 2 o $^{\star}$, S Nepal, Makwampur distr., 35 km W Hetaura, 300 m, 22.ii.1995, leg. K. Mikkola \& A. Wikberg; FMNH; 1 o $^{*}$ NW Pokhara Birethanti, 1300 m, 29.vii.1996, leg. M. Fibiger; ZMUC; $1 \delta^{\star}$, Central Nepal, $15 \mathrm{~km} \mathrm{~S} \mathrm{Barpak} \mathrm{Baluuea,} 850$ m, 10.vii.1998, leg. M. Fibiger; SDEI. Erstfund, bisher (nach Diakonoff, 1968) aus Sri Lanka, Indien, Miamar, China und von den Philippinen bekannt.

\section{Bemerkung:}

Die neue Art ähnelt der aus Burma beschriebenen E. platyntis (MeYrick, 1894), sie unterscheidet sich aber von dieser durch die Form der Sklerotisierung an den Socii sowie durch das Vorhandensein einer feinen Bestachelung des Costalrandes der Valve. Die Form der Socii sowie der Valven ist variabel (siehe Fig. 73-79).

\section{Edosa clavifera sp. n. (Fig. 15; 80-82)}

Typus. Holotypus o, Nepal, Prov. Chisapani Garhi, Bhainse Dobhan, 730 m, 16.-20.vii.1967, leg. Dierl-Schacht, Gen. Präp. R. Gaedike Nr. 7171; - Paratypen: 3 ㅇ, mit den gleichen Angaben. Der Holo- und 2 Paratypen in der ZSM, 1 Paratypus im SDEI.

\section{Beschreibung (Fig. 15):}

Spannweite 14-16 mm; Stirnschopf zitronengelb (nur teilweise erhalten); Antenne fast weiß, Scapus mit Pecten; Labialpalpen hellbraun, außen etwas dunkler als innen, 2. Glied mit einigen Borsten; Thorax, Tegulae und Vorderflügel hellbraun, Basis der Tegulae und Costalrand an der Basis dunkler; Hinterflügel hellgrau. 
○ Genital (Fig. 80): Uncus mit zwei Socii mit breiter Basis, S-förmig geschwungen, in der Mitte schlanker werdend, das Ende stärker sklerotisiert und keulenartig erweitert; Tegumen und Vinculum breit ringförmig, Hinterkante gerandet; Valve höher als breit, Ventralrand breit verrundet endend, Costalrand kürzer, mit sehr kleinen Zähnchen besetzt, Außenrand sichelförmig eingebuchtet; Phallus so lang wie die Valve hoch, mit breiter runder Basis, ab 1/2 schlanker werdend, mit runder Spitze; Anellus mit der Innenseite des Vinculum verbunden.

† Genital (Fig. 81-82): Ventraläste der Apophysen spangenartig verbunden, Seiten bestachelt, Dorsaläste mit dem VIII. Tergit verbunden, dieses in einem breiten Bereich ebenfalls bestachelt; Ostium ohne deutliche Kennzeichnung; am Ende des Ductus bursae die für viele Arten der Gattung typische Sklerotisierung mit zwei spitz endenden leicht gebogenen Zapfen, die aus einer sklerotisierten Platte hervorragen, sie sind umgeben von einer komplexen Bildung aus stark sklerotiserten Spangen und Streifen am Anfangsteil des Corpus bursae.

Etymologie: Der Name (lat.: "clava" - "die Keule" und "fero" - "tragend") bezieht sich auf die Form der Socii.

\section{Bemerkung:}

Die Form der Socii sowie der Valve unterscheidet die neue Art eindeutig von den Nachbararten.

\section{Edosa synaema (MEYRICK, 1905)}

\section{Untersuchtes Material:}

Pakistan: 2 ơ $^{\star}$ Hazara Manshera, 15 km n Taxilla, 600 m, 14.x.1988, 3353'N, 7256'E, leg. Hacker; coll. Derra; SDEI; $10^{\star}$, Pakistan, Salt Range, 4 km nw Choa Saidan, 800 m, 10.x.1988, $32^{\circ} 46^{\prime} \mathrm{N}, 73^{\circ} 03^{\prime} \mathrm{E}$, leg. Hacker; coll. Derra.

Erstfund, bisher nur vom Typenfundort (Sri Lanka) und aus Nepal bekannt.

\section{Bemerkung:}

Die übliche Schreibweise des Namens weicht von der in der Originalbeschreibung ab. Ich schließe mich der Meinung von Sattler (i. 1.) an und bleibe hier bei dieser veränderten Form. Herr SATTLER schrieb mir hierzu:

"Sie haben schon recht, der Name ist eindeutig synoema geschrieben, obgleich die Zeitschrift durchaus auch das ae (æ) im Drucksatz hatte. MeYrick hat aber später diese Namen selbst immer mit ae geschrieben, und daran haben wir uns [Museum of Natural History, London] in der Regel gehalten. Auch Clarke hat in seinem Katalog der MeYrick-Mikros die ae Schreibweise verwendet. MeYrick war durchaus nicht immer konsequent in der Umwandlung der oe zu ae ..."

Edosa dierli sp. n. (Fig. 16; 83-84)

Typus. Holotypus ơ, Nepal, Prov. Chisapani Gorhi, Bhainse Dobhan, 730 m, 16.-20.vii.1967, leg. Dierl-Schacht, Gen. Präp. R. Gaedike Nr. 4395; ZSM.

Beschreibung (Fig. 16):

(Falter etwas abgeflogen) Spannweite $11 \mathrm{~mm}$; Stirnschopf strohgelb, Antenne weißlich, ohne Pecten; Labialpalpen außen dunkler als innen, 2. Glied mit einigen Borsten; Thorax, Tegulae und 
Costa des Vorderflügels an der Basis dunkelbraun, der übrige Flügel hell gelblichbraun, Fransen dunkler; Hinterflügel dunkelgrau.

○ Genital (Fig. 83-84): Uncus mit zwei kurzen Socii, spitz endend, mit Längsfalte; Tegumen und Vinculum breit ringförmig, Außenrand stärker sklerotisiert; Valve zweigeteilt: Basalteil langgezogen, verrundet rechteckig, Ventralseite bis zur Mitte mit zahlreichen spitzen Dornen besetzt; dorsal mit einem kugelförmigen separierten Costalteil mit einer nach oben ausgezogenen Spitze; Phallus durch den Anellus an der Innenseite des Vinculum befestigt, schlank, spitz endend.

† Genital: Unbekannt.

Etymologie: Benannt zu Ehren von Dr. Wolfgang Dierl.

\section{Bemerkung:}

Die Form der Valve ist bisher innerhalb der Gattung unbekannt.

Edosa hackeri sp. n. (Fig. 17; 85)

Typus. Holotypus $0^{\top}$, Indien, Himachal Pradesh, Kohi Pura, sso Bilaspur, 51 ${ }^{\circ} 15^{\prime} \mathrm{N}, 76^{\circ} 65^{\prime} \mathrm{E}$, 24.xi.1992, leg. Hacker \& Peks, Gen. Präp. R. Gaedike Nr. 7132; - Paratypus: $10^{\top}$ mit den gleichen Daten.

Der Holotypus in der coll. Derra, der Paratypus im SDEI.

Beschreibung (Fig. 17):

Spannweite $11 \mathrm{~mm}$; Stirnschopf gelb, Antenne etwas heller; Labialpalpen außen dunkel, innen hellgelb, 2. Glied mit einigen Borsten; Thorax und Tegulae tief dunkelbraun; Vorderflügel gelb, Fransen mit einigen dunkleren Schuppen, Costa von der Basis bis fast 1/2 dunkelbraun; Hinterflügel hellgrau.

$0^{\star}$ Genital (Fig. 85): Uncus mit zwei kurzen Socii mit runden Spitzen; Tegumen und Vinculum breit ringförmig, Hinterkante des Vinculum stärker sklerotisiert, in der Mitte eingesenkt; Valve klein, fast quadratisch mit verrundeten Ecken, Costalrand am Apex mit einem stark sklerotisierten dreieckigen Zahn; Phallus sehr lang, Basis breit, dahinter bis zur Spitze schmal, stark gebogen, gelenkig mit der Innenseite des Vinculum verbunden.

† Genital: Unbekannt.

Etymologie: Benannt nach Herrmann Hacker, einem der Sammler der neuen Art.

\section{Bemerkung:}

Die Form des Phallus unterscheidet die neue Art von den anderen aus Nepal bekannten Vertretern der Gattung.

\section{Edosa orphnodes (MEYRICK, 1911)}

\section{Untersuchtes Material:}

Nepal: $1 \sigma^{\star}$, Prov. Nr. 2 East Jiri, 2000 m, 10.viii.1967, leg. W. Dierl; ZSM; 1 o $^{\star}$ NW Pokhara Birethanti, 1300 m, 29.vii.1996, leg. M. Fibiger; ZMUC.

Erstfund, bisher nur aus Indien bekannt. 


\section{Edosa exhausta (MeYRICK, 1917)}

\section{Untersuchtes Material:}

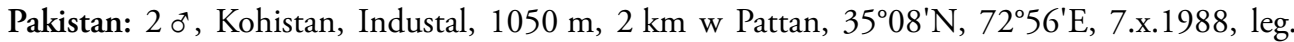
H. Hacker, coll. Derra; SDEI; Indien: $40^{*}$, Himachal Pradesh, Kullu Valley, oberhalb Kullu, $1500 \mathrm{~m}, 31^{\circ} 57^{\prime} \mathrm{N}, 77^{\circ} 09^{\prime} \mathrm{E}, 22 . x .1990$, leg. H. Hacker, coll. Derra; SDEI.

Erstfunde, bisher auch aus dem Iran und aus Afghanistan bekannt.

\section{Edosa opsigona (MeYRICK, 1911) (Fig. 86-89)}

\section{Untersuchtes Material:}

Nepal: 6 ơ 2 + , Rapti Tal, Jhawani 200 m, 15.v., 14.-19.v.1967, leg. Dierl-Forster-Schacht, ZSM, SDEI; 4 \% , Rapti Tal, Monahari Khola, Belwa, 350 m, 6., 11., 12., 5.-12.v.1967, leg. Dierl-Forster-Schacht, ZSM, SDEI; 1 \%, Prov. Chisapani Gari, Chisapani Garhi, 1600 m, 11.-15.vii.1967, leg. Dierl-Schacht, ZSM; 1 o , Chitwan: Sauraha, UV 25.v.1986, leg. J. Minet \& J. Orousset, MNHN; 1 क , Central Nepal, 15 km S Barpak Baluuea, 850 m, 10.vii.1998, leg. M. Fibiger; ZMUC; Pakistan: $30^{*}, 2$ \% , Obere Indusebene, $3 \mathrm{~km}$ n Dhak Pathan, $500 \mathrm{~m}$, 13.x.1988, 330ำ $\mathrm{N} 72^{\circ} 56^{\prime} \mathrm{O}$, leg. Hacker, coll. G. Derra, SDEI; Indien: $10^{\star}, 1$ ㅇ, Rajastan, $22 \mathrm{~km}$ ö. Shahpura, westl. Bairat, 800 m, 27 $26^{\prime} \mathrm{N}, 7^{\circ} 09^{\prime} \mathrm{E}, 27 . x i .1992$, leg. Hacker \& Peks, coll. Derra.

Die Serie enthielt auch Weibchen, so dass hier das 9 Genital erstmals beschrieben werden kann (Fig. 86-89): Ventraläste der Apophysen münden im VIII. Sternit, dieses lateral bestachelt, Dorsaläste enden im VIII. Tergit, dieses in der apikalen Hälfte bestachelt; Ostium mit zwei kleinen schmalen sklerotisierten Halbringen, die gattungstypische Sklerotisierung am Ende des Ductus bursae variabel (siehe Fig. 87-89).

\section{Edosa spinosa sp. n. (Fig. 18; 90)}

Typen. Holotypus ơ , Pakistan, Hazara, 1300 m, Abbottabad, 34 $13^{\prime} \mathrm{N}, 7^{\circ} 14^{\prime} \mathrm{E}, 23 . / 24 . i x .1988$, leg. Hacker; - Paratypen: $1 \sigma^{\star}$, mit den gleichen Angaben; $10^{\star}$, Nepal, $30 \mathrm{~km}$ E Kathmandu, 900 m, 1.iii.1995, leg. K. Mikkola.

Der Holotypus in der coll. Derra, 1 Paratypus im FMNH, 1 Paratypus im SDEI.

Beschreibung (Fig. 18):

Spannweite $11 \mathrm{~mm}$; Stirnschopf hellgelb, Scapus und die ersten Glieder des Flagellum ebenfalls hellgelb, das übrige Flagellum heller; Labialpalpen außen dunkler, innen etwas heller; Thorax und Tegulae dunkelbraun, Vorderflügel gelb, Schuppen auf den Fransen mit dunklen Spitzen, Costa an der Basis dunkelbraun; Hinterflügel grau.

$0^{\star}$ Genital (Fig. 90): Uncus mit zwei sehr kleinen Socii mit runder Basis und dünnen, nach außen gebogenen Spitzen; Tegumen und Vinculum breit ringförmig, Hinterrand des Vinculum in der Mitte vorgewölbt, der Gesamtrand stark sklerotisiert; Valve deutlich größer als Uncus-Tegumen, zweigeteilt: Costalarm kurz, mit breiter Basis, zur stumpfen Spitze nach unten gebogen, auf der Innenseite mit zahlreichen kurzen Stacheln, der übrige Valvenkörper mehr als doppelt so lang wie der Costalarm, von der schmalen Basis bis hinter die Mitte stark erweitert, convex, dorsal ein stumpfes Dreieck bildend, ventral leicht konkav bis zur ausgezogenen apikalen Spitze, diese mit 
längeren dicken Borsten besetzt; Phallus etwas länger als die Vinculumbreite, schlank, zur Spitze leicht gebogen, durch den Anellus mit der Vinculuminnenseite verbunden.

† Genital: Unbekannt.

Etymologie: Benannt nach der Bestachelung des Costalarms der Valve (lat.: "spinosus" - "stachelig").

\section{Bemerkung:}

Die sehr kleinen Socii sowie die Form der Valve unterscheidet die neue Art eindeutig von den bisher bekannten Vertretern der Gattung, ähnliche Valvenbildungen haben einige Arten aus Südostasien, die Robinson (2008) beschrieb.

Edosa fibigeri sp. n. (Fig. 19; 91-92)

Typus. Holotypus ơ , Nepal, NW. Pokhara, Birethanti, 1300 m, 29.vii.1996, leg. M. Fibiger, Gen. Präp. R. Gaedike Nr. 7366; ZMUC.

Beschreibung (Fig. 19):

Spannweite $25 \mathrm{~mm}$; Stirnschopf hellgelb, über den Palpen fast weiß, Antenne hellbraun, die ersten zwei Glieder der Labialpalpen dunkelbraun, 3. Glied heller, 2. Glied mit einigen Borsten; Thorax und Tegulae dunkelbraun, apikal hellbraun; Vorderflügel hellbraun, Costa an der Basis dunkler; Hinterflügel graubraun.

$0^{\star}$ Genital (Fig. 91-92): Uncus mit zwei langen schlanken Socii, Innenseite stärker sklerotisiert, Spitzen rund; Tegumen und Vinculum breit ringförmig, apikale Kante gerandet; Valve so lang wie Uncus-Tegumen-Vinculum, mit großer gerandeter Transtilla, Basalteil mit sklerotisierten Leisten, Costalrand leicht konvex, mit etwas ausgezogener stumpfer Spitze, Ventralrand vor 1/2 leicht ausgebuchtet, danach leicht konkav, apikal stumpf verrundet, etwas kürzer als der Costalrand; Phallus so lang wie die Valve, basal breit verrundet, zur stumpfen Spitze gleichmäßig schmaler werdend.

† Genital: Unbekannt.

Etymologie: Benannt zu Ehren von Michael Fibiger, dem Sammler des Typus.

\section{Bemerkung:}

Die Form der Valve macht die neue Art unterscheidbar von den anderen Vertretern der Gattung aus Nepal.

\section{Edosa caerulipennis (ERSCHOFF, 1874)}

\section{Untersuchtes Material:}

Pakistan: $1 \sigma^{\star}$, NW-Frontier prov. Swat, 14.-28.vii.2008, leg. Abdul Rehman Azeemi, coll. Dunny Nilsson; ZMUC.

Erstfund, bisher bekannt auch aus dem Iran, aus Afghanistan, Turkmenistan und Indien. 
Edosa nestoria (MEYRICK, 1910) (Fig. 93-95)

\section{Untersuchtes Material:}

Indien: $10^{\star}, 3$ ㅇ Kashmir, 10 km N Srinagar, Nat. Park Dachigam, 15.-21.vii.1982, leg. E. \& M. Arenberger; NMW. Erstfund, bisher auch bekannt aus Afghanistan und Pakistan.

Das Material wurde vor längerer Zeit von PETERSEN untersucht, die seinerzeit von ihm angefertigten Zeichnungen des bisher unbekannten weiblichen Genitals werden hier erstmals abgebildet und beschrieben (Fig. 93-95):

Ventraläste der Apophysen bilden ein breites Band, Dorsaläste münden in das bestachelte VIII. Tergit; Anfangsteil des Ductus bursae stärker sklerotisiert, in der Bursa ein Signum aus einem nach innen fein gezähnten Ring mit einer kleinen scheibenförmigen Sklerotisierung.

\section{Perissomastix (Aphrodoxa) peterseni (AMSEL, 1959) (Fig. 96)}

\section{Untersuchtes Material:}

Pakistan: $5 o^{\star}$, Salt Range, $3 \mathrm{~km}$ nw Khewra, $700 \mathrm{~m}, 32^{\circ} 44^{\prime} \mathrm{N}, 73^{\circ} 04^{\prime} \mathrm{E}, 11 . x .1988$, leg. H. Hacker, coll. Derra; SDEI; - $1 \mathrm{o}^{\star}$, Hazara Manshera, $15 \mathrm{~km}$. Taxilla, $600 \mathrm{~m}, 33^{\circ} 53^{\prime} \mathrm{N}$, 72 56'E, 14.x.1988, leg. H. Hacker, coll. Derra; - 1 ơ $^{\circ}$, Obere Indusebene, 3 km n Dhak Pathan, 500 m, 13.x.1988, 330' N 7256'O, leg. Hacker, coll. G. Derra.

Indien: $10^{*}, 2$ ㅇ, Rajastan, 2 km n Ajmer, 400 m, 26²8'N, 74³8'E, 28.xi.1992, leg. Hacker \& Peks, coll. Derra; SDEI; - $10^{\star}$, Rajastan, Distr. Jodhpur, $10 \mathrm{~km}$ ö. Binawas, Salzsteppe, $28^{\circ} 15^{\prime} \mathrm{N}$, 7326'E, 1.xii.1992, leg. Hacker \& Peks, coll. Derra: Erstfund für Indien. Bisher auch aus dem Iran und aus Afghanistan nachgewiesen.

Die Serie enthielt auch ein Weibchen, so dass hier das \& Genital erstmals beschrieben werden kann (Fig. 96): Ventraläste der vorderen Apophysen zungenartig zum Ostiumbereich hin verlängert, lateral mit einem bestachelten Feld, Dorsaläste in beborsteten dreieckigen Fortsätzen endend; hintere Apophysen mit je einer bestachelten Verbreiterung unterhalb der Analpapillen, diese dreieckig, Hinterrand eingebuchtet.

Der Bau ähnelt dem bei Perissomastix amseli (Petersen, 1959), die Einbuchtungen der Analpapillen sind aber nicht so deutlich, die Verbreiterung der hinteren Apophysen ist größer und nur mit kleinen Stacheln besetzt und der Ostiumbereich ist zungenartig verlängert.

\section{Praelongicera afghana (PETERSEN, 1959)}

\section{Untersuchtes Material:}

Nepal: $1 \sigma^{\star}$, Gandaki, Ghasa, 2050 m, 2.viii.1996, leg. M. Fibiger; ZMUC; Pakistan: 1 o $^{\star}$,

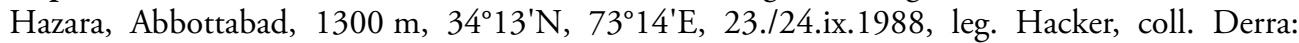
Erstfunde für beide Länder. Bisher nur aus Afghanistan nachgewiesen.

\section{Cephimallota densoni RoBInson, 1986}

\section{Untersuchtes Material:}

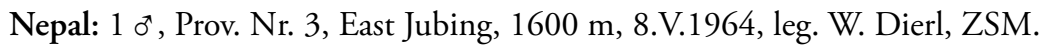

Erstfund außerhalb der Typenserie. 
Tineola bisselliella (Hummel, 1823)

\section{Untersuchtes Material:}

Nepal: 1 ㅇ, Kathmandu-Chauni, 1400 m, 13.iv.1967, leg. Dierl, Forster \& Schacht, ZSM.

\section{Tinea translucens MEYRICK, 1917}

\section{Untersuchtes Material:}

Nepal: 1 ㅇ, Kathmandu-Chauni, 1400 m, 22.vii.1962, leg. Dierl, Forster \& Schacht, ZSM.

\section{Tinea nepalica sp. n. (Fig. 20; 97-101)}

Typus. Holotypus ơ, Nepal, Prov. Nr. 3 East Khumjung, 3800 m, 15.vi.1964, leg. W. Dierl, Gen. präp. R. Gaedike Nr. 7152; - Paratypus: 1 ㅇ, vom gleichen Fundort, aber 24.vi.1964, leg. W. Dierl; Afghanistan; 1 \%, $12 \mathrm{~km}$ SE Jomson, Chauri Kharka, 4100 m, 8.-9.viii.1996, leg. M. Fibiger.

Der Holo- und ein Paratypus in der ZSM, ein Paratypus in ZMUC.

Beschreibung (Fig. 20):

Spannweite $20 \mathrm{~mm}\left(\mathrm{o}^{*}\right), 24 \mathrm{~mm}$ ( ( ); Stirnschopf hell gelblichbraun, Antennen graubraun, Labialpalpen hell gelblichbraun, 2. Glied apikal mit einigen Borsten; Thorax hell graubraun, Tegulae dunkler, apikal heller; Vorderflügel glänzend hell graubraun, mit dunkel graubrauner Zeichnung. Dunkel sind die Costa von der Basis 1/3, je ein Fleck über der Zelle bei $1 / 3$ und am Ende der Zelle, der Apex sowie die gesamte Fransenbasis; Hinterflügel hellgrau.

$0^{\star}$ Genital (Fig. 97-99): Uncus schalenförmig, Gnathosarme abgewinkelt, spitz endend, miteinander verbunden, Tegumen schmal, Vinculum mit langem schlanken Saccus; Valve so lang wie der Saccus, Gesamtumriss etwa dreieckig, Costalrand leicht konvex, Ventralrand bei 1/2 am breitesten, mit einer stumpfen Ausbuchtung, von da bis zum verrundeten Apex gleichmäßig schmaler werdend; Innenseite mit einem bestachelten Feld von der Basis der Transtilla bis zur Mitte, über der ventralen Ausbuchtung eine kurze sklerotisierte Leiste; Phallus doppelt so lang wie die Valve, gerade, Vesica mit zahlreichen kleinen Zähnchen.

\& Genital (Fig. 100-101): Vordere Apophysen enden in einer sklerotisierten Platte mit zwei spitzen Zipfeln, Ostiumbereich ventral mit einer sichelförmigen sklerotisierten Leiste umgeben, in der Bursa zahlreiche kleine Dornen.

Etymologie: Benannt nach dem Land des Fundortes.

\section{Bemerkung:}

Im Bau des Genitalapparates bestehen Ähnlichkeiten zu T. semifulvelloides Petersen, 1973, es fehlt aber im männlichen Genital die Aufwölbung des Vinculum, der Saccus ist schmaler, die Valve besitzt ein bestacheltes Feld auf der Innenseite und die Zähnchen in der Vesica sind viel kleiner und nicht verschieden groß. Im weiblichen Genital ist die sichelförmige sklerotisierte Leiste des Ostiumbereiches charakteristisch. 


\section{Niditinea striolella (MATSUMURA, 1931)}

\section{Untersuchtes Material:}

Nepal: $1 \sigma^{\star}$, Kathmandu, éclairage urbain., 3.viii.1982, leg. J. Boudinot \& J. Minet, MNHN; 2 ㅇ, Prov. Nr. 3, East Jubing, 1600 m, 20.-23.vii.1964, leg. W. Dierl, ZSM.

\section{Crypsithyris arenbergerarum sp. n. (Fig. 21; 102-105)}

Typus. Holotypus ${ }^{\star}$, Kaschmir, $15 \mathrm{~km}$ W Kangan, Wangan, 16./17.7.[19]82, [leg.] M. u. E. Arenberger; Paratypen: $8 \sigma^{\star}, 2$ ㅇ, mit den gleichen Angaben.

Der Holo- und 6 Paratypen im NMW, 4 Paratypen im SDEI.

Beschreibung (Fig. 21):

Spannweite 10-12 mm; Stirnschopf und Antenne hell graubraun; Labialpalpen ebenfalls hell graubraun, innen etwas heller, 2. Glied apikal mit einigen Borsten; Thorax und Tegulae basal etwas dunkler, sonst graubraun; Vorderflügel hellgrau, auf der gesamten Fläche mit verstreuten dunkleren Schuppen, gehäuft in der apikalen Hälfte; am Ende der Zelle ein unscharf begrenzter dunkler Fleck, Costa an der Basis dunkel; Hinterflügel hellgrau.

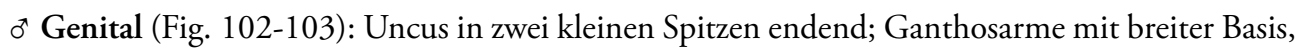
in der Mitte deutlich schmaler werdend, in gebogene Spitzen auslaufend; Saccus gerandet, apikal deutlich schmaler werdend, das Ende eckig, gerade abgeschnitten, etwas breiter als der Schaft; Valve langgestreckt, schmal, am Unterrand bei 1/2 lappenförmig gerundet ausgebuchtet, Apex breit gerundet; Phallus so lang wie Uncus-Tegumen-Saccus, subapikal etwas schmaler werdend, in der Vesica sehr kleine schuppenartige Sklerotisierungen.

\& Genital (Fig. 104-105): Vordere Apophysen dorsal in einer zweizipfelichen beborsteten Platte endend; Ostium unterhalb eines mit langen Borsten besetzten, mehr oder weniger trapezförmigen Bandes; im Ductus bursae am Anfang eine unregelmäßig ringförmige Sklerotisierung, darunter ein Feld mit kleinen dicken Dornen, gefolgt von einer Fläche mit mehreren langen nadelförmigen Borsten, es fehlt die sonst für die Gattung charakteristische Signumbildung.

Etymologie: Benannt nach dem Ehepaar Ernst und Margarete Arenberger, den Sammlern der Art.

\section{Bemerkung:}

Äußerlich nicht sicher von den anderen Arten der Gattung zu unterscheiden. Im männlichen Genital bestehen Ähnlichkeiten zu enixa МeYrick, 1921, mesodyas МeYrick, 1907, japonica Petersen \& Gaedike, 1993, hoenei Petersen \& Gaedike, 1993 und hebeiensis Xiao \& Li, 2005, die Form der lappenförmigen Ausbuchtung der Valve ist aber deutlich anders. Die bisher bekannten Weibchen besitzen alle in der Bursa eine komplexe Signumbildung, die hier fehlt.

Crypsithyris nepalicola sp. n. (Fig. 22; 106-108)

Typus. Holotypus ơ, Nepal, Prov. Nr. 3 East Jubing, 1600 m, 20.-23.vii.1964, leg. W. Dierl, Staatsslg. München; Gen. präp. Gaed.[ike] Nr. 4422; Paratypus: 1 ㅇ, vom gleichen Fundort.

Die Typen in der ZSM. 
Beschreibung (Fig. 22):

Spannweite 8-9 mm; Stirnschopf rahmfarben, Scapus mit Pecten; Labialpalpen innen rahmfarben, außen etwas dunkler, 2. Glied apikal mit einigen Borsten; Thorax und Tegulae rahmfarben, Basis etwas dunkler; Vorderflügel auf rahmfarbenem Grund mit verstreuten dunkleren Schuppen, am Ende der Zelle einen dunklen Fleck bildend, Basis der Costa ebenfalls dunkel; Hinterflügel weißlich glänzend.

o Genital (Fig. 106-107): Uncus spitz endend, ohne Einkerbung; Gnathosarme lang, hinter der Mitte abgewinkelt, vor der stumpfen Spitze etwas breiter werdend; Saccus gerandet, gleichmäßig bis zur flach dreieckigen Spitze schmaler werdend; Valve basal am breitesten, Costalrand leicht conkav, Ventralrand bei $1 / 2$ leicht aufgewölbt, Außenrand gleichmäßig verrundet; Phallus fast so lang wie Uncus-Tegumen-Saccus, im letzten Drittel schlanker als basal, in der Vesica mit kaum sichtbaren Sklerotisierungen.

† Genital (Fig. 108): Vordere Apophysen dorsal in einer konischen Platte endend, apikal tief eingesenkt, seitlich je ein beborsteter Zipfel; Ostium trichterförmig, mit feinkörniger Sklerotisierung, seitlich in ein beborstetes Band übergehend; Ende des Ductus bursae mit sklerotisiertem Ring, am Anfang des Corpus bursae ein sklerotisierter Ring mit 9 sehr langen spitzen Nadeln, darunter, ringförmig angeordnet, mehrere paarweise angeordnete kurze Dornen, dazwischen sehr dünne, kaum sichtbare Sklerotisierungen.

Etymologie: Benannt nach dem Land des Fundortes.

\section{Bemerkung:}

Von den Arten mit einer ventralen Ausbuchtung der Valve (siehe oben) durch die Form der Gnathosarme deutlich unterschieden.

Crypsithyris cornuta sp. n. (Fig. 23; 109)

Typus. Holotypus ơ , Nepal, Prov. Nr. 3 East Jubing, 1600 m, 11.v.1964, leg. W. Dierl, Staatsslg. München; Gen. präp. Gaed.[ike] Nr. 4425.

Der Holotypus in der ZSM.

Beschreibung (Fig. 23):

Spannweite $10 \mathrm{~mm}$; Stirnschopf dunkel rahmfarben, Scapus mit Pecten aus dünnen Schuppen, Labialpalpen außen rahmfarben, innen fast weiß, 2. Glied apikal mit einigen Borsten; Thorax und Tegulae hell rahmfarben, mit dunkler Basis; Vorderflügel auf rahmfarbenem Grund mit verstreuten dunklen Schuppen, gehäuft in der apikalen Hälfte, am Ende der Zelle ein dunkler Fleck; Hinterflügel weißlich glänzend.

$0^{\star}$ Genital (Fig. 109): Uncus spitz, schnabelförmig endend, Gnathosarme mit breiter verrundeter Basis, leicht gebogen, bis zur Spitze schmaler werdend; Saccus gerandet, gleichmäßig schmaler werdend, apikal eckig; Valve mit breiter Basis, Ventralrand bei 1/2 mit undeutlicher stumpfer Aufwölbung, zur verrundeten Spitze hin schmaler werdend; Phallus deutlich länger als Uncus-Tegumen-Saccus, Basis breiter, gerade, mit zwei stabförmigen Cornuti und sehr kleinen Sklerotisierungen in der Vesica.

क Genital: Unbekannt.

Etymologie: Benannt wegen des Besitzes von Cornuti im Phallus. 


\section{Bemerkung:}

Die beiden langen Cornuti sind charakteristisch für die neue Art.

\section{Monopis artasyras MEYRICK, 1931}

\section{Untersuchtes Material:}

Nepal: 1 ㅇ Helmu-Gebiet, Gusum Banjyang, 2600 m, 1.ix.1967, leg. W. Dierl, ZSM; 1 ๙ $^{\star}$, Nepal, Gandaki above Old Marpha, 3450 m, 12.viii.1996, leg. M. Fibiger, ZMUC.

\section{Monopis longella (WALKER, 1863)}

\section{Untersuchtes Material:}

Nepal: 16 ơ, 6 q , Kathmandu - Chauni, 1400 m, 17.-20., 22., 25., 28., 29.iv., 1., 2., 3., 27., 29.v., 25.vi., 22.vii.1967, leg. Dierl-Forster-Schacht, ZSM, SDEI; $20^{\star}$, Kathmandu Valley, Godavani, 1600-1800 m, 6.vi.1967, leg. Dierl-Forster-Schacht, ZSM; 1 o $^{\star}$, Kathmandu Valley, Rani Ban: Icangu, 1400 m, 24.vii.1982, leg. J. Boudinot \& J. Minet, MNHN; 1 o $^{\star}$, Prov. Chisapani Garhi Chisapani Garhi, 1600 m, 11.-15.vii.1967, leg. Dierl-Forster-Schacht, ZSM; 1 ơ $^{\star}$ Prov. Nr. 3 East Junbesi 2750 m, 25.-31.vii.1964, leg. Dierl, ZSM; 1 올 Prov. Nr. 3 East Jubing, 1600 m, 20.-30.vii.1964, leg. Dierl, ZSM; 1 ㅇ, C-Nepal, Kali-Gangaki-Tal, Choklopani, nördlich Tukche, 2600 m, 23.vi.1973, leg. Dierl-Lehmann, ZSM; 1 o, Nepal, 8 km SE Jomson Thadung, 3500 m, 7.viii.1996, leg. M. Fibiger, ZMUC: Erstfund, bisher nachgewiesen aus dem Iran, aus Pakistan, China, Japan und dem Fernen Osten Russlands.

\section{Monopis monachella (HüBNER, 1796)}

\section{Untersuchtes Material:}

Nepal: $8 \sigma^{\star}$, Kathmandu Valley, Rani Ban: Icangu, 1400 m, 21., 24.vii.1982, leg. J. Boudinot \& J. Minet, SDEI, MNHN; $1 \sigma^{\star}$, Ilam: Mai Khola, 22.vi.1986, leg. J. Minet \& J. Orousset, MNHN; 1 o, 30 km E Kathmandu, 900 m, 1.iii.1995, leg. K. Mikkola, FMNH; 2 o $^{\star} 1$ ㅇ, Markwampur distr., 35 km W Hetaura, 300 m, 22.ii.1995, leg. K. Mikkola \& A. Wikberg, FMNH; SDEI.

\section{Monopis avara MEYRICK, 1919}

\section{Untersuchtes Material:}

Nepal: $1 \sigma^{*}$, Prov. Chisapani Garhi Chisapani Garhi, 1600 m, 11.-15.vii.1967, leg. DierlForster-Schacht, ZSM; 1 o $^{*}$, Kathmandu Valley, Godavari, 1600-1800 m, 5.-7.viii.1967, leg. Dierl-Forster-Schacht, ZSM; 1 ơ, Kathmandu-Chauni, 1400 m, 29.iv.1967, leg. DierlForster-Schacht, SDEI; $10^{\star}$, Bhimpedi, $400 \mathrm{~m}, 4 .-7 . i v .1962$, leg. G. Ebert \& H. Falkner; ZSM; 1 ㅇ, S Nepal, Makwampur distr., 35 km W Hetaura, 300 m, 22.ii.1995, leg. K. Mikkola $\&$ A. Wikberg, FMNH; 1 o $^{*}$ Nepal, Centr. N, Ganesh Himal, Khurpudanda pass, W slope, 3700 m, 18.x.1995, leg. M. Fibiger, ZMUC; 1 specimen without abdomen, Nepal, Centr. N, Mailung Khola, 1050 m, 24.x.1995, leg. M. Fibiger, ZMUC; Pakistan: 1 o, Hazara Manshera, 
Thakot, $800 \mathrm{~m}, 34^{\circ} 40^{\prime} \mathrm{N}, 73^{\circ} 03^{\prime} \mathrm{E}, 8 . x .1988$, leg. H. Hacker, Coll. Derra; Indien: $10^{\star}, 1$ \%,

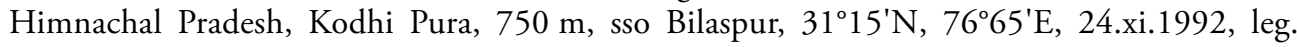
Hacker \& Peks, coll. Derra.

\section{Gerontha dracuncula MeYRICK, 1928}

\section{Untersuchtes Material:}

Nepal: $1 \sigma^{\star}$, Rapti Tal, Jhawani, 200 m, 17.v.1967, leg. Dierl-Forster-Schacht: Erstfund, bisher nachgewiesen aus China und Thailand.

\section{Danksagung und verwendete Abkürzungen}

Die Arbeit war nur möglich durch die Großzügigkeit der Kollegen, die es mir ermöglichten, das Material über einen sehr langen Zeitraum auszuleihen. Das waren aus der Zoologischen Staatssammlung München die Herren Wolfgang Dierl ( $\dagger$ ) und Andreas Segerer, aus dem Nationalmuseum Paris Herr Joel Minet, aus dem Zoologischen Museum Kopenhagen Herr Ole Karsholt und aus dem Museum Helsinki Herr Lauri Kaila. Weiteres Material stellten mir die Herren Georg Derra/Deckendorf und Ernst Arenberger/ Wien zur Verfügung. Ein besonderer Dank gilt Herrn Kevin R. Tuck/Natural History Museum London, der mir Typenmaterial für Vergleichszwecke ausgeliehen hat. Herrn Christian Kutzscher /Müncheberg (SDEI) sei gedankt für die Anfertigung der Farbfotografien der neuen Arten.

Die Abkürzungen entsprechen den in der Liste "Insect and Spider Collections of the World" des Bishop Museum/Honolulu verwendeten (http//hbs.bishopmuseum.org/codens).

coll. Derra coll. Georg Derra, Reckendorf, Deutschland

FMNH Finnish Museum of Natural History (L. KaILA), Helsinki, Finnland

MNHN Muséum National d'Histoire Naturelle (J. Minet), Paris, Frankreich

NMW Naturhistorisches Museum (M. LöDL), Wien, Österreich

SDEI Senckenberg Deutsches Entomologisches Institut, Müncheberg, Deutschland

ZMUC Zoological Museum (O. Karsholt), Copenhagen, Dänemark

ZSM Zoologische Staatssammlung (A. Segerer), München, Deutschland

\section{Literatur}

Diakonoff, A. N. 1968: Microlepidoptera of the Philippine Islands. - United States National Museum Bulletin 257 (1967): 1-484.

Petersen, G. 1982: Tineiden aus Nepal (Lepidoptera, Tineidae). - Reichenbachia Staatliches Museum für Tierkunde Dresden 20 (8): 73-76, 10 Fig.

Robinson, G. S. 2008: Hidden diversity in small brown moths - the systematics of Edosa (Lepidoptera: Tineidae) in Sundaland. - Systematics and Biodiversity 6 (3): 319-384, 187 figs.

Robinson, G. S.; Sattler, K.; Shaffer, M.; Tuck, K. R. \& Allen, M. G. 1995: Microlepidoptera and Pyraloidea of Nepal - a checklist and bibliography. - Tinea 14 (Supplement 2): 150-181.

Anschrift des Verfassers:

Dr. Reinhard Gaedike

Florusstraße 5

53225 Bonn, Germany

email: tinagma@msn.com

\section{Subject editor:}

O. Karsholt 

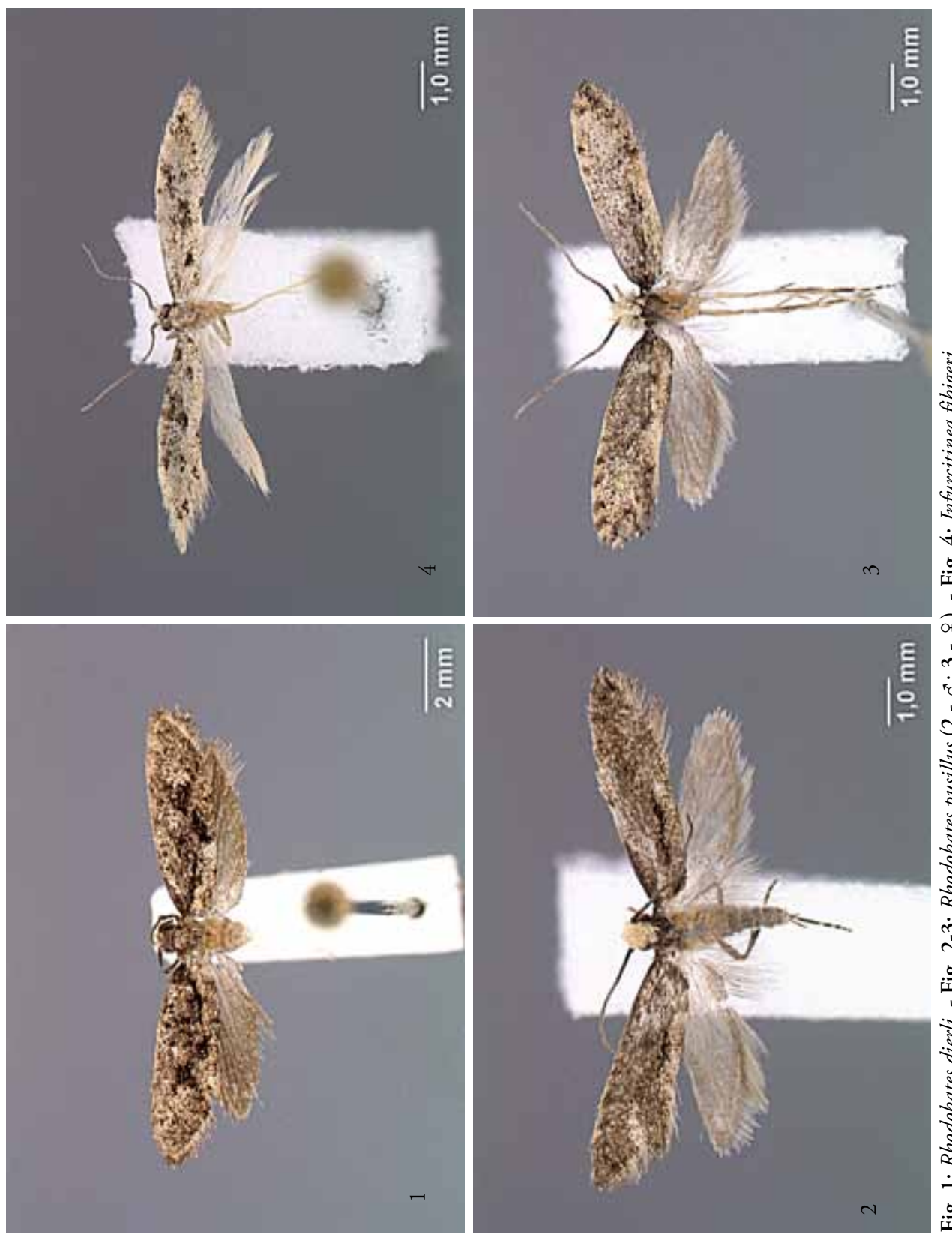

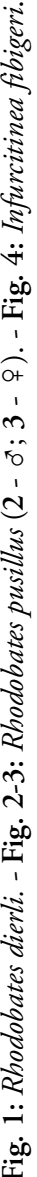




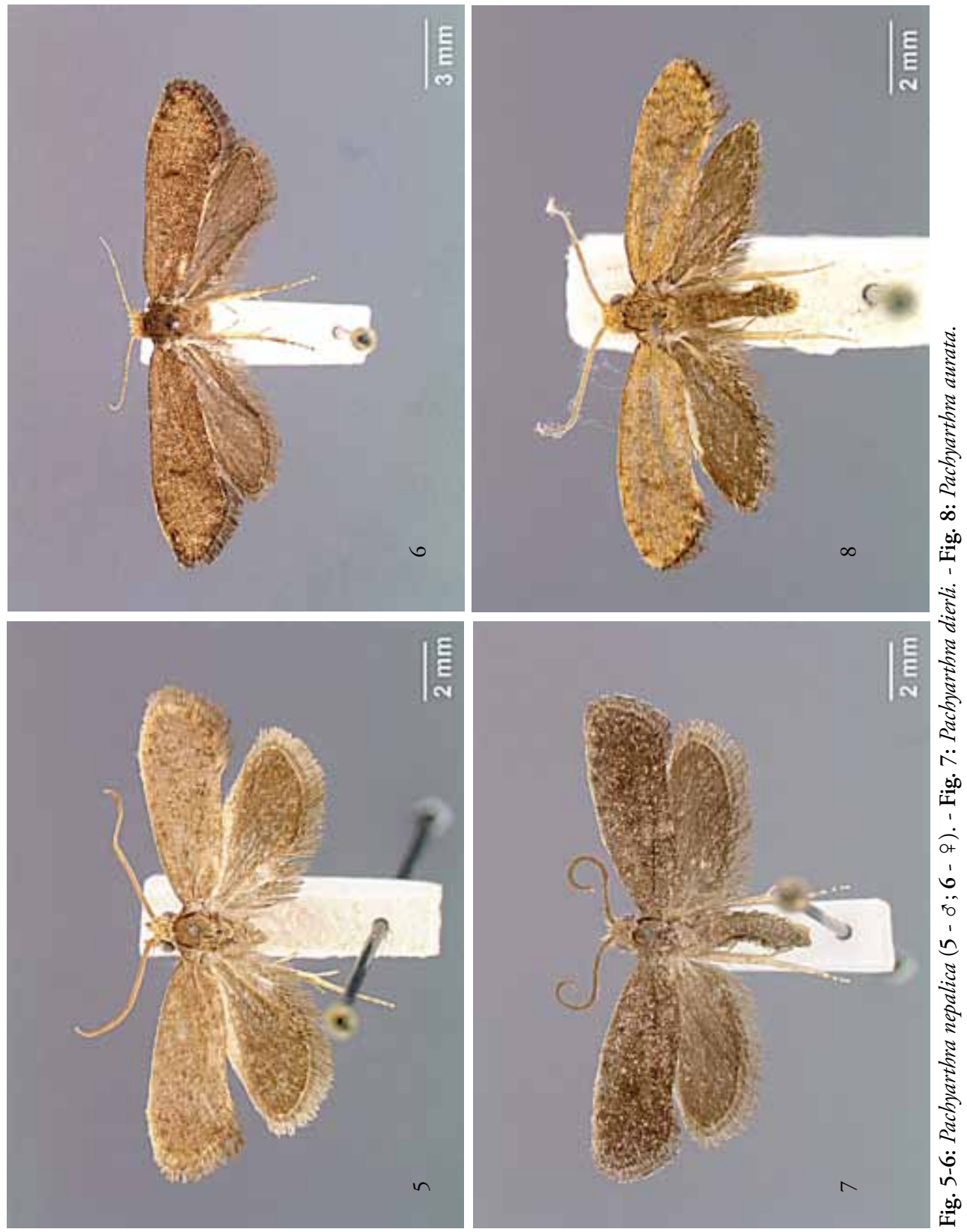



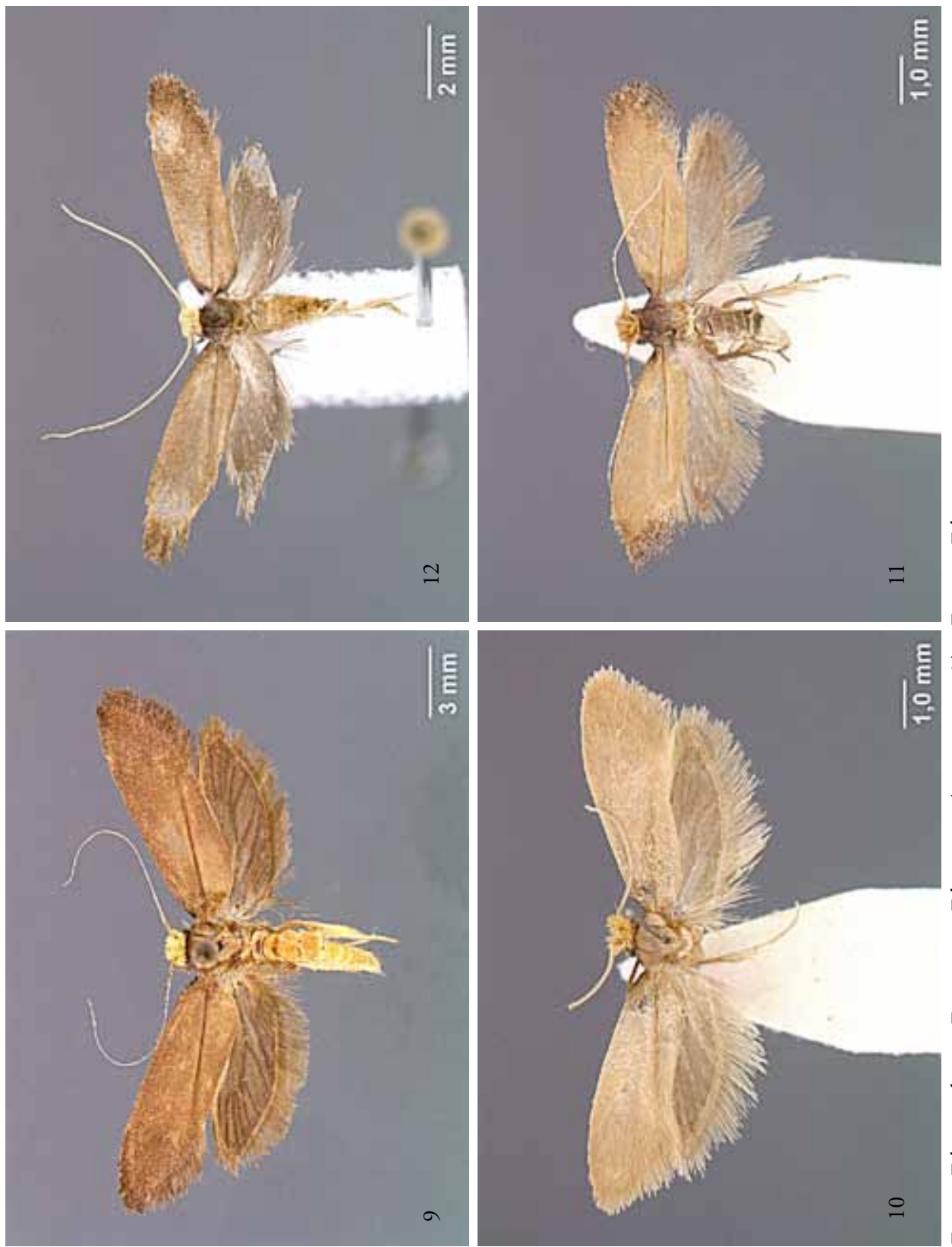

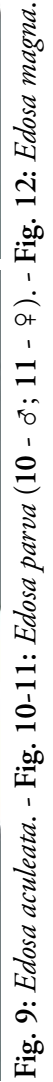




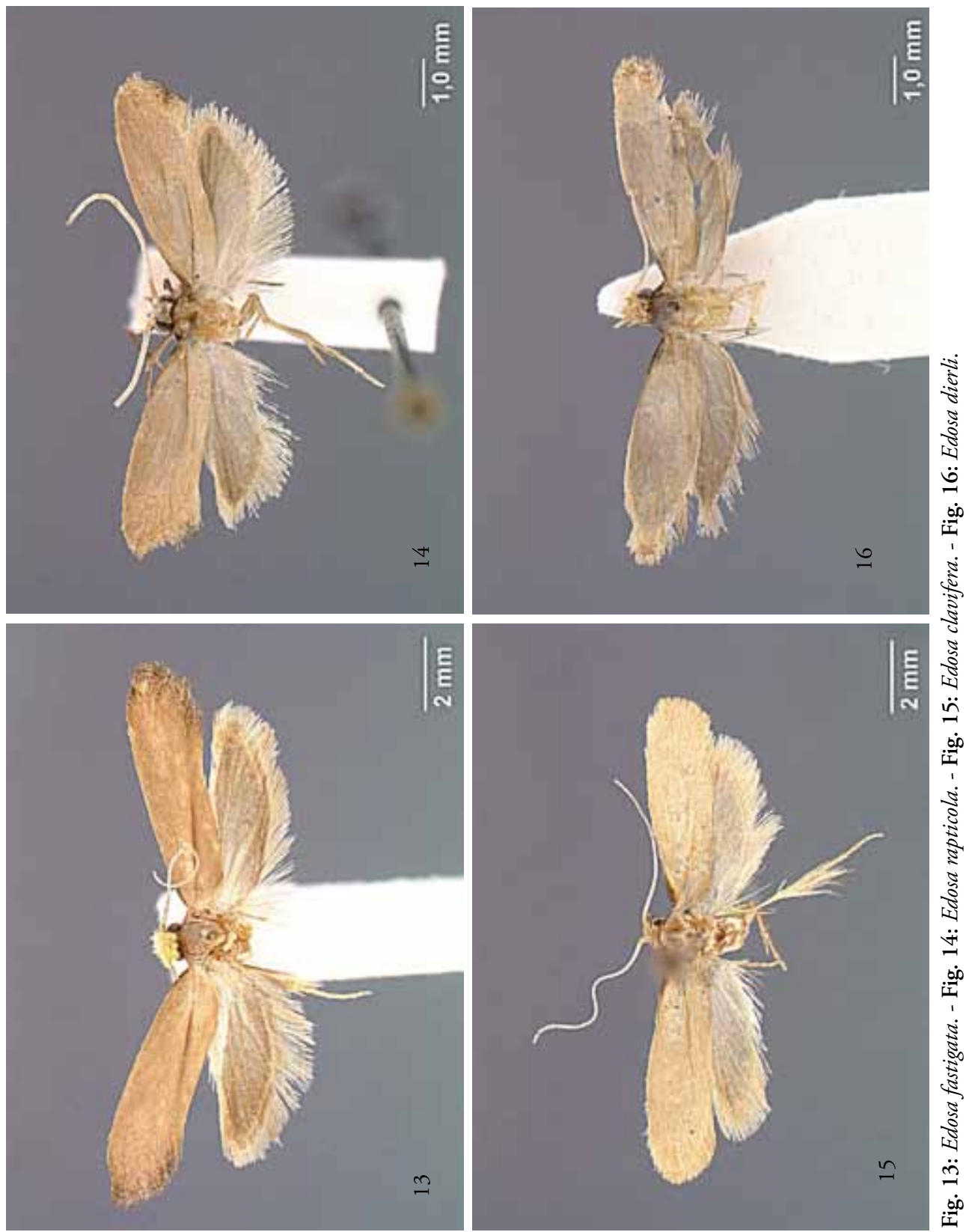



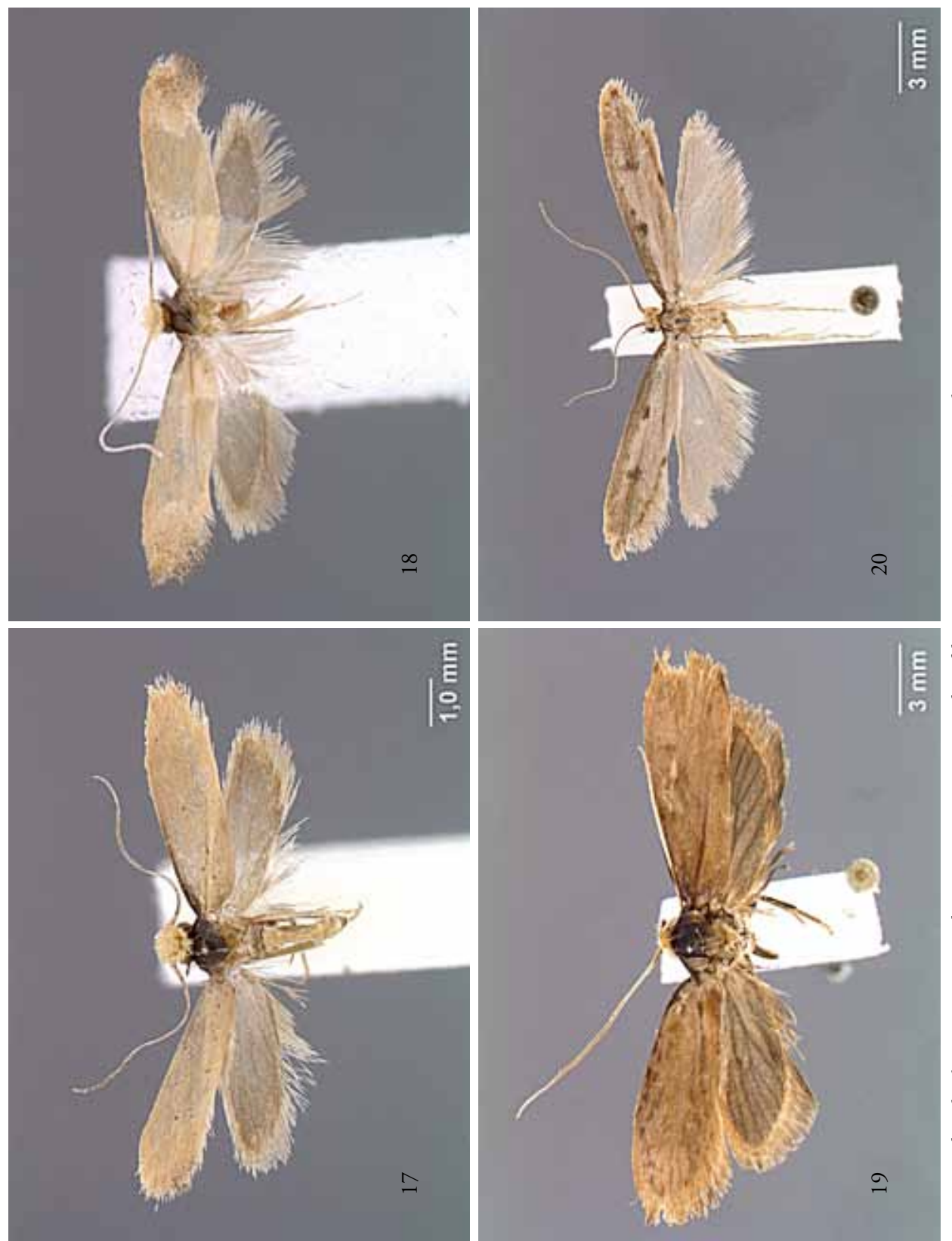

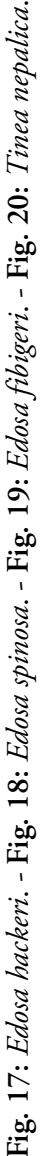



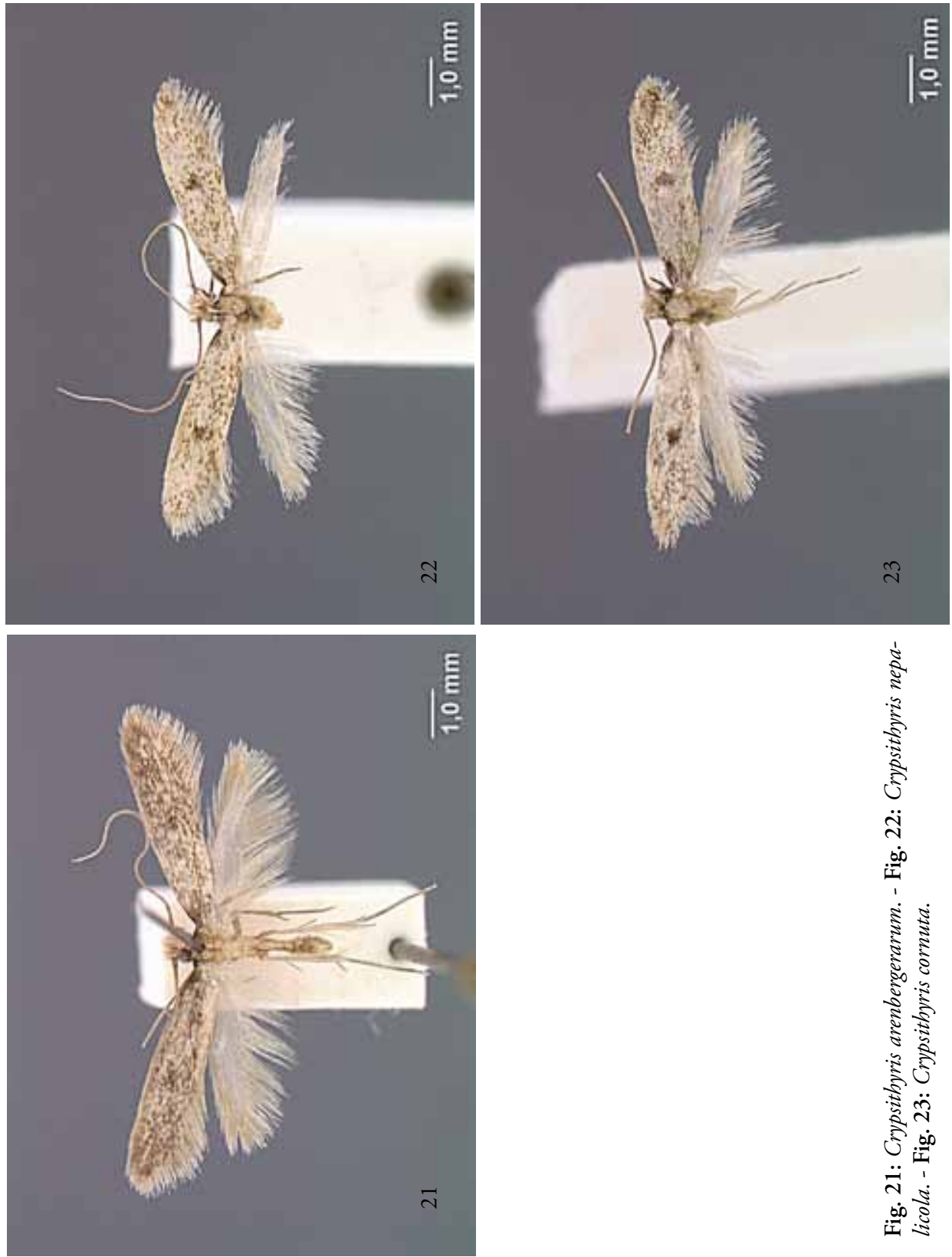

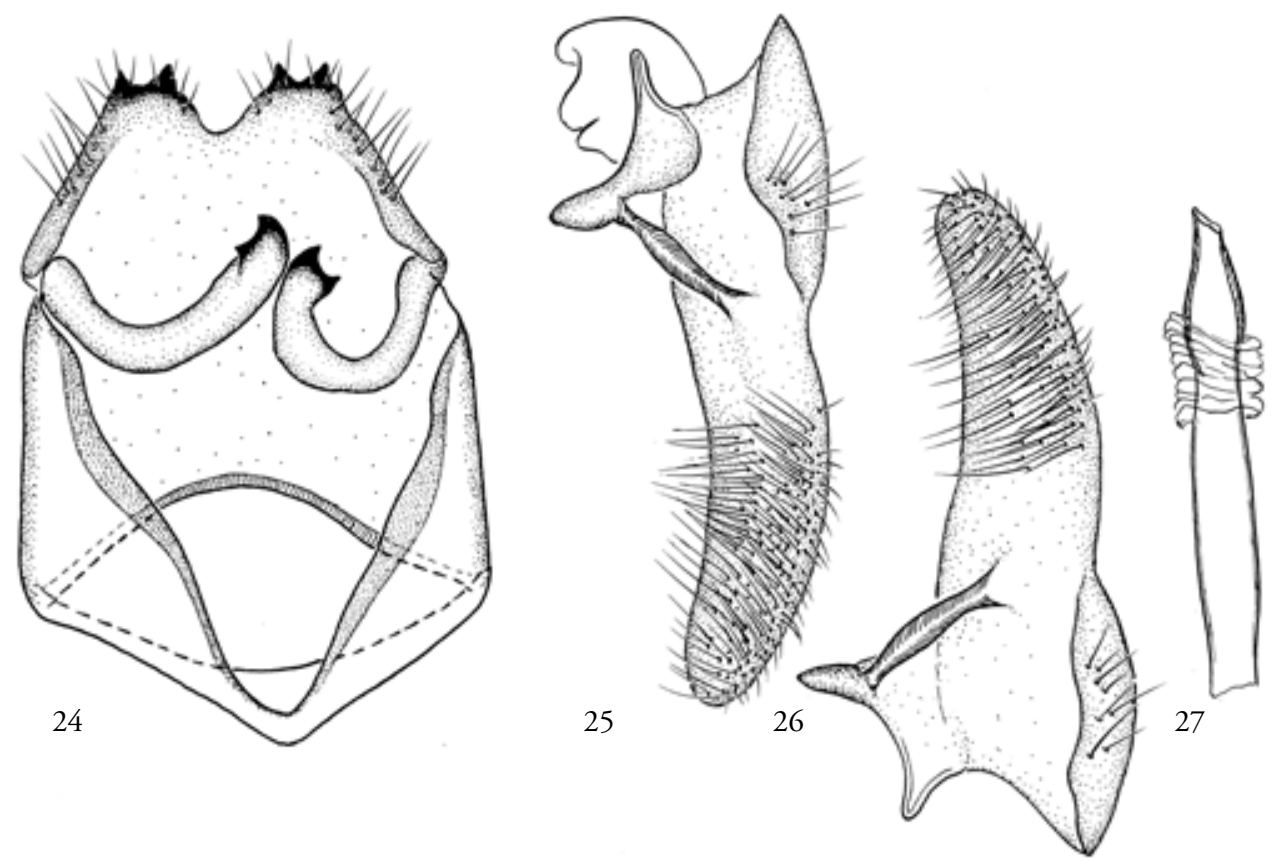

Fig. 24-27: Rhodobates dierli, ơ (24 - Uncus-Tegumen; 25-26 - Valven; 27 - Phallus).
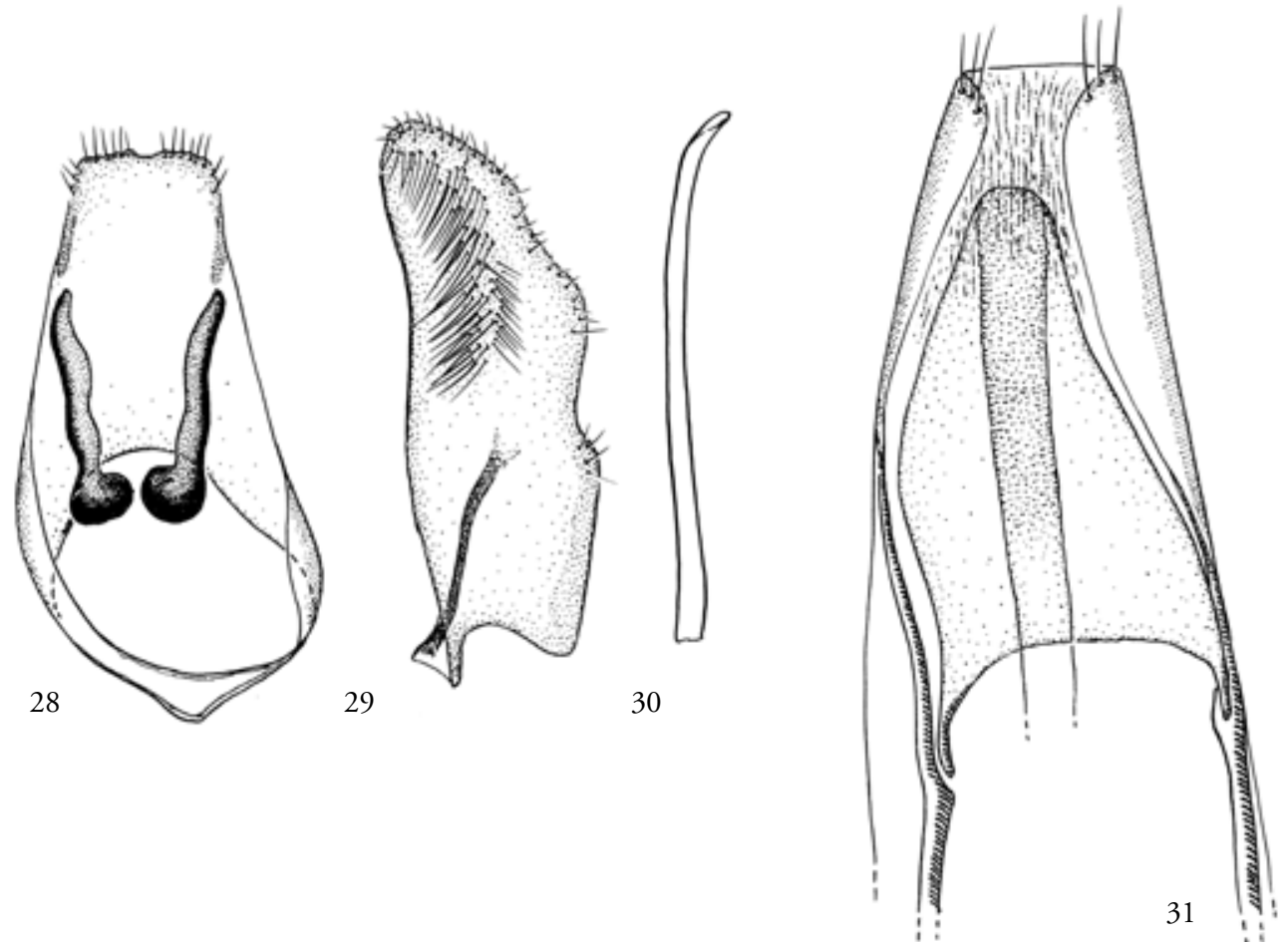

Fig. 28-31: Rhodobates pusillus (o': 28 - Uncus-Tegumen; 29 - Valve; 30 - Phallus; 31 - १). 


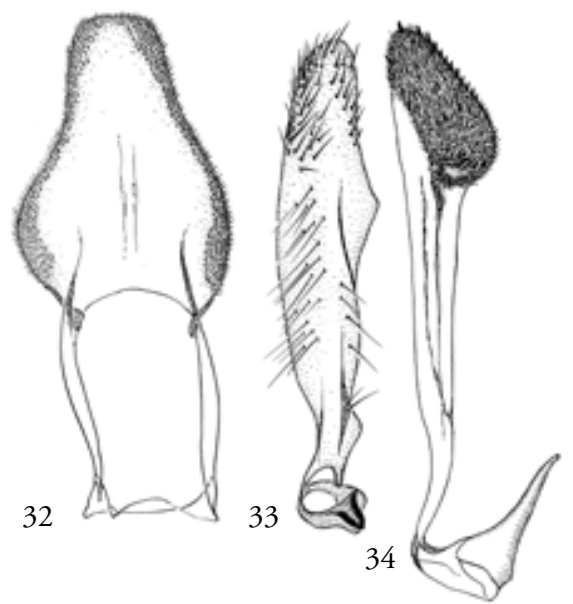

Fig. 32-34: Infurcitinea fibigeri, ơ (32 - UncusTegumen; 33 - Valve; 34 - Phallus-Anellus).

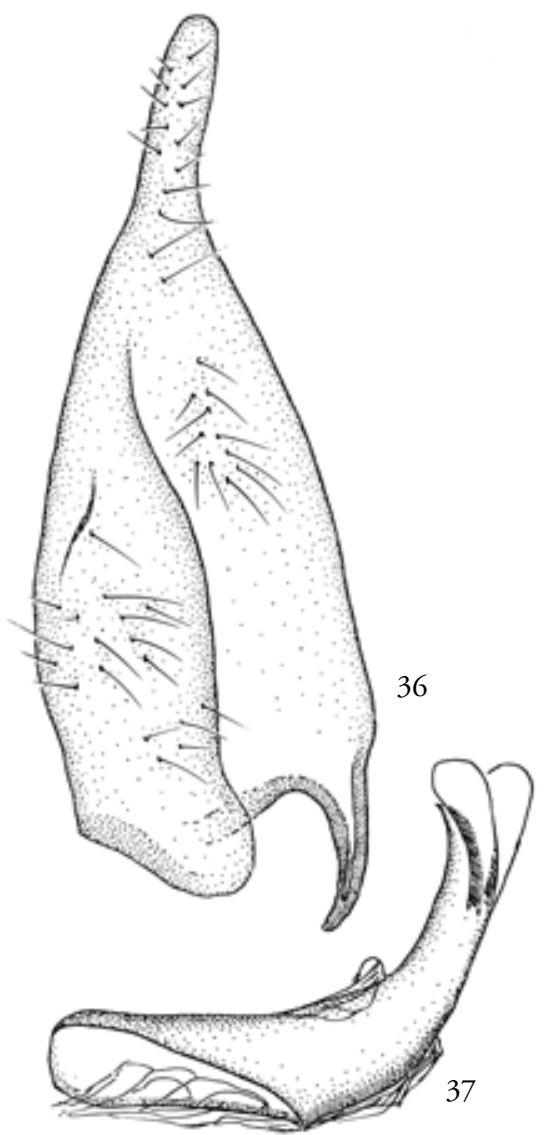

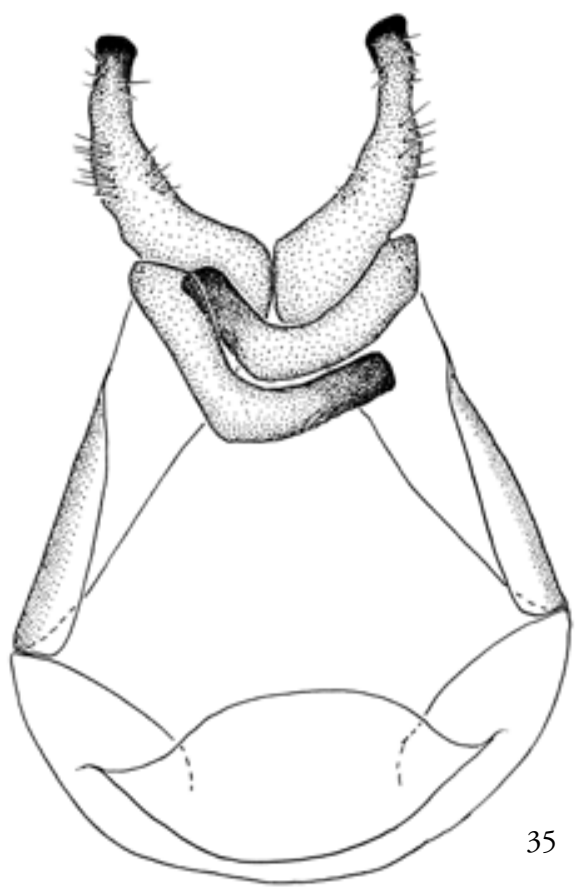

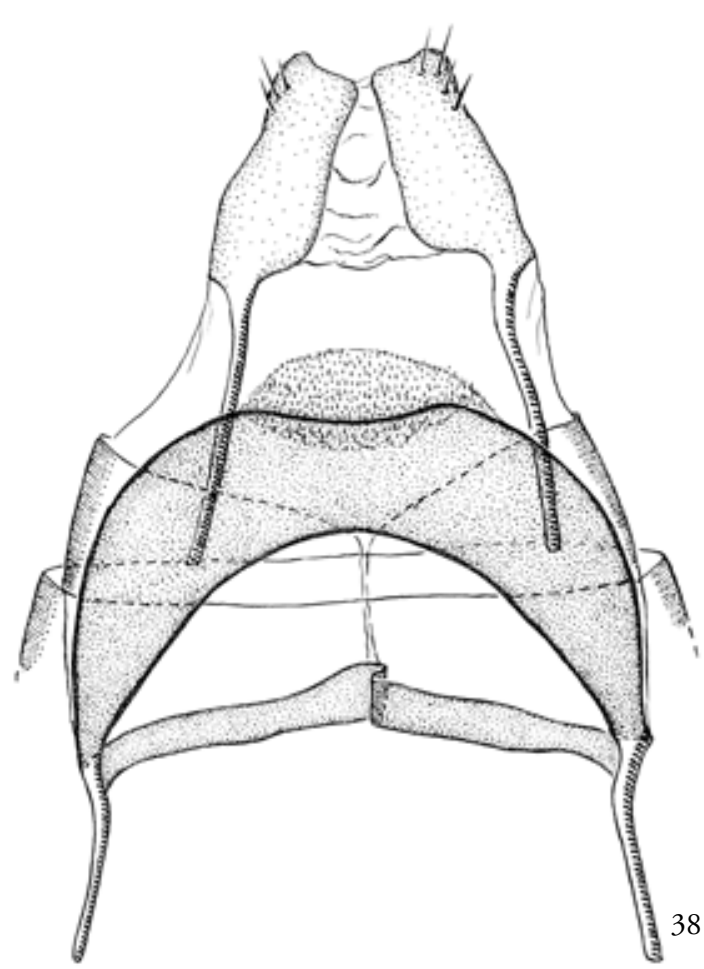

Fig. 35-38: Pachyarthra nepalica (o: 35 - Uncus-Tegumen; 36 - Valve; 37 - Phallus; 38: ㅇ). 

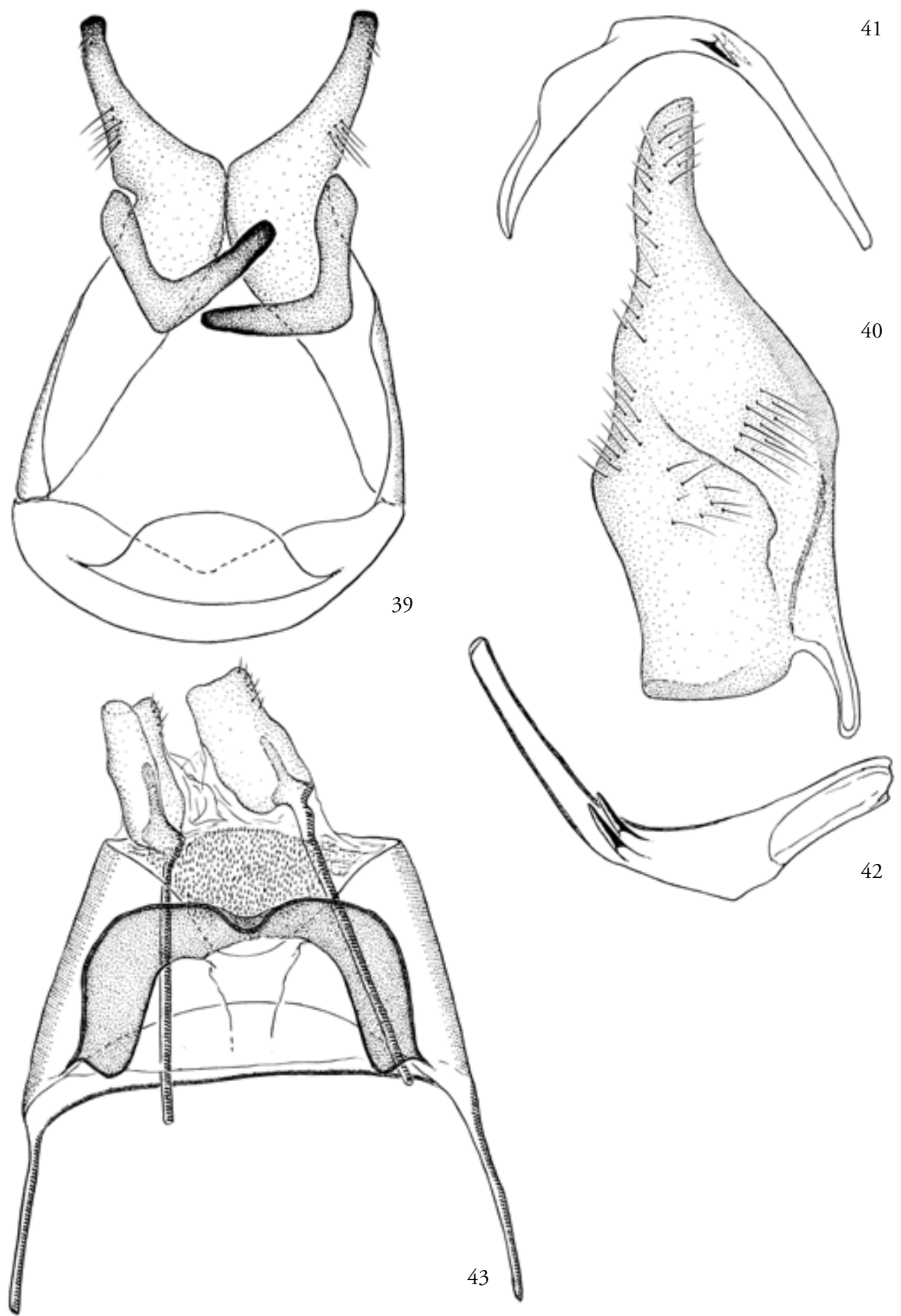

Fig. 39-43: Pachyarthra dierli ( $0^{*}: 39$ - Uncus-Tegumen; 40 - Valve; 41-42 - Phallus, präparationsbedingte Unterschiede; 43: 우). 

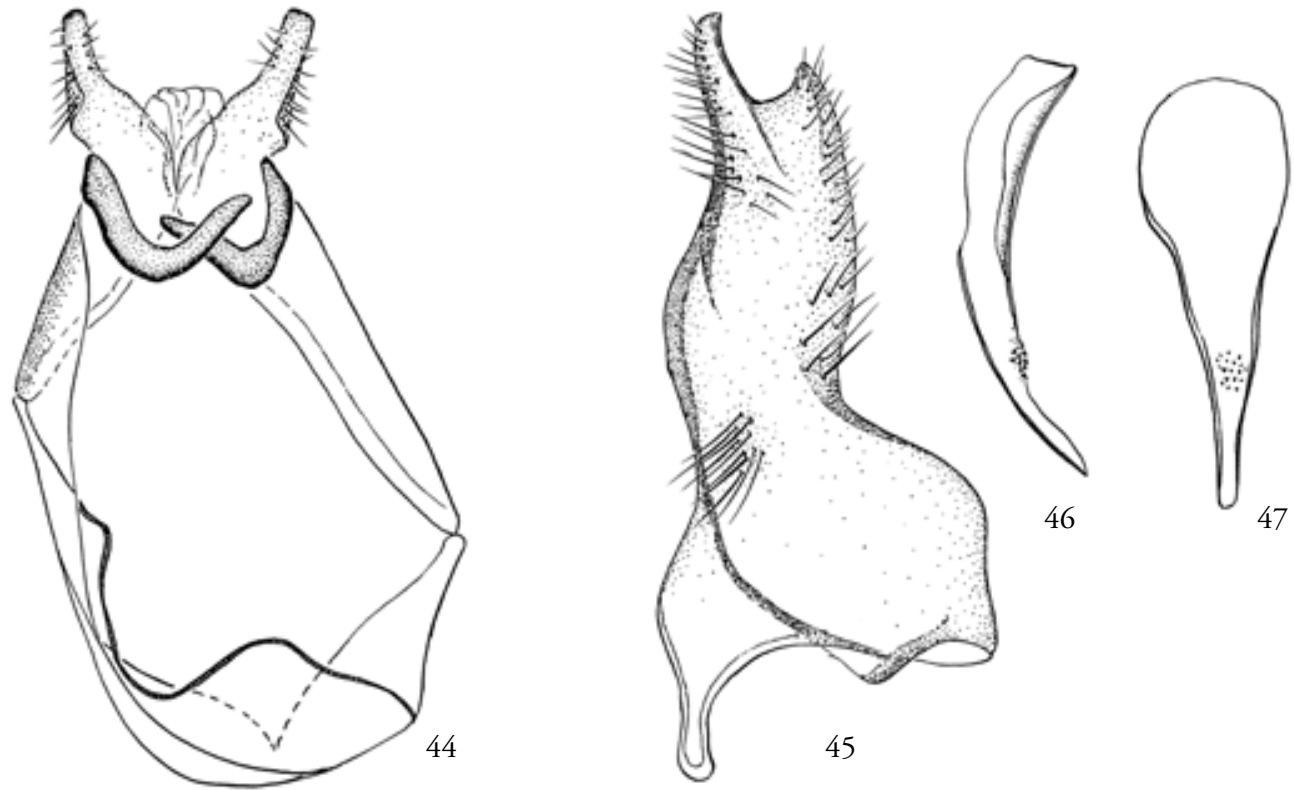

Fig. 44-47: Pachyarthra aurata, ơ (44 - Uncus-Tegumen; 45 - Valve; 46-47 - Phallus lateral und ventral).

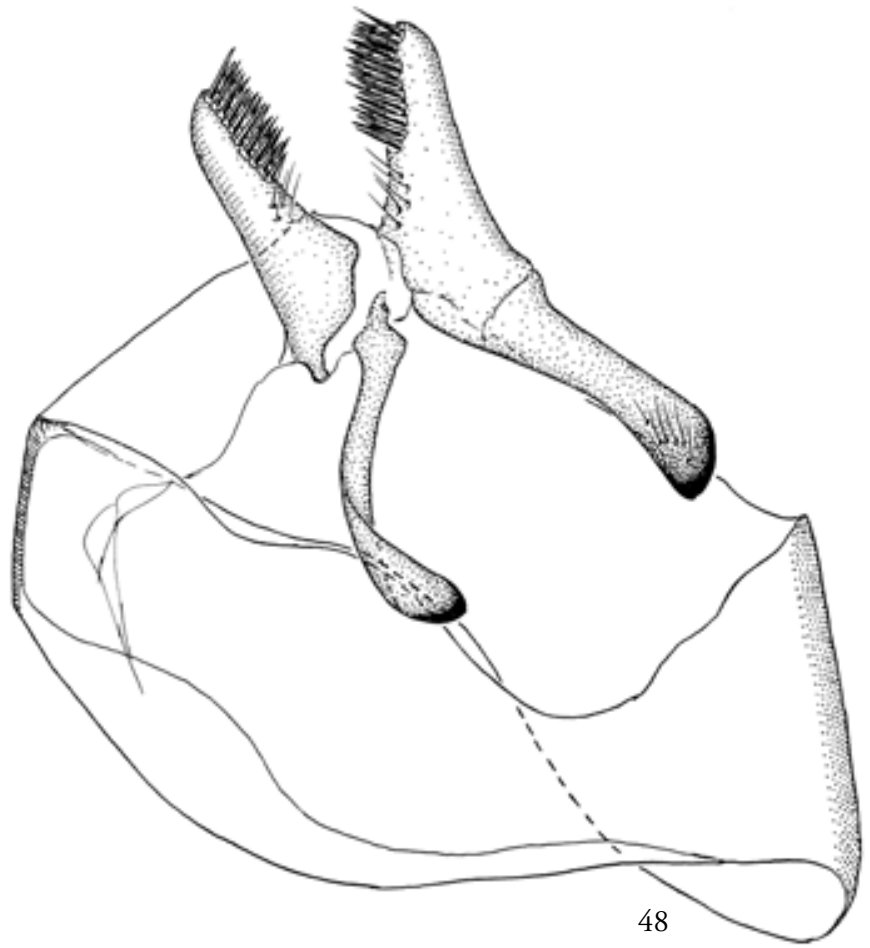

Fig. 48: Edosa aculeata (o : 48 - Uncus-Tegumen). 

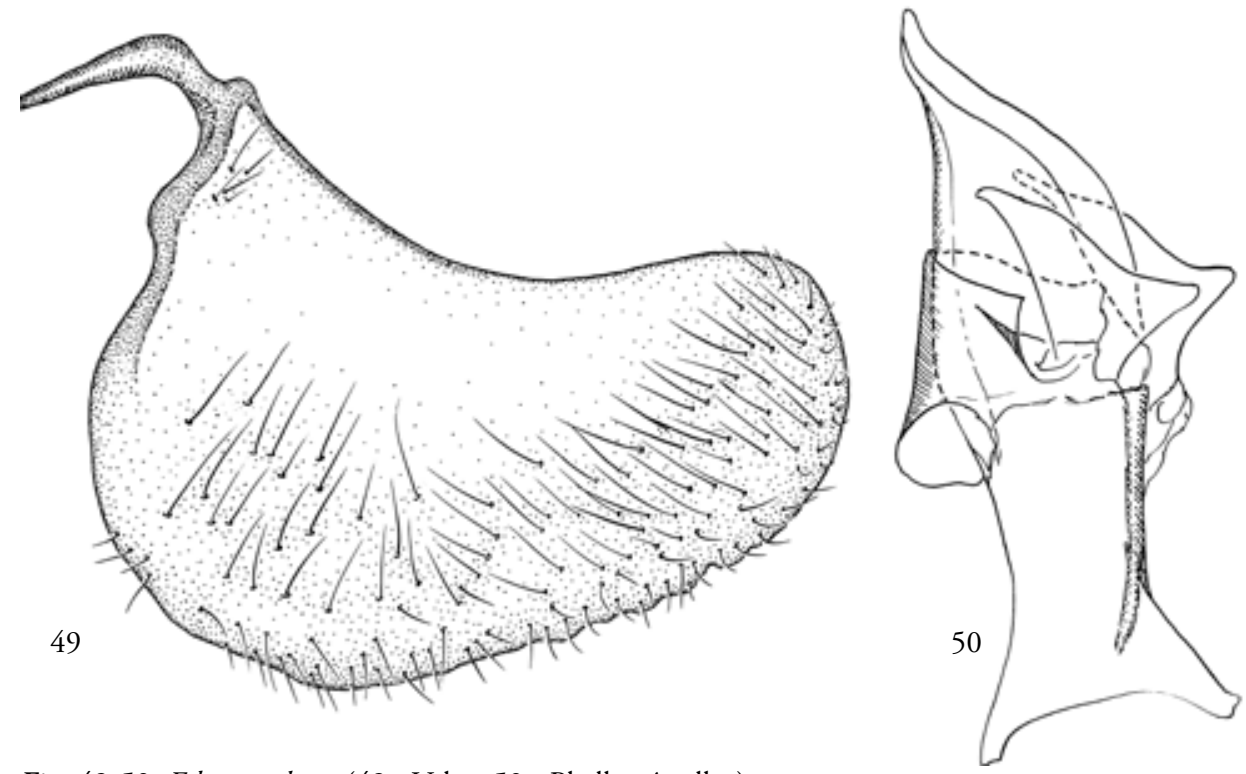

Fig. 49-50: Edosa aculeata (49 - Valve; 50 - Phallus-Anellus).

Fig. 51-52: Edosa aculeata (: 51 - VIII. Segment; 52 - Ductus und Corpus bursae).
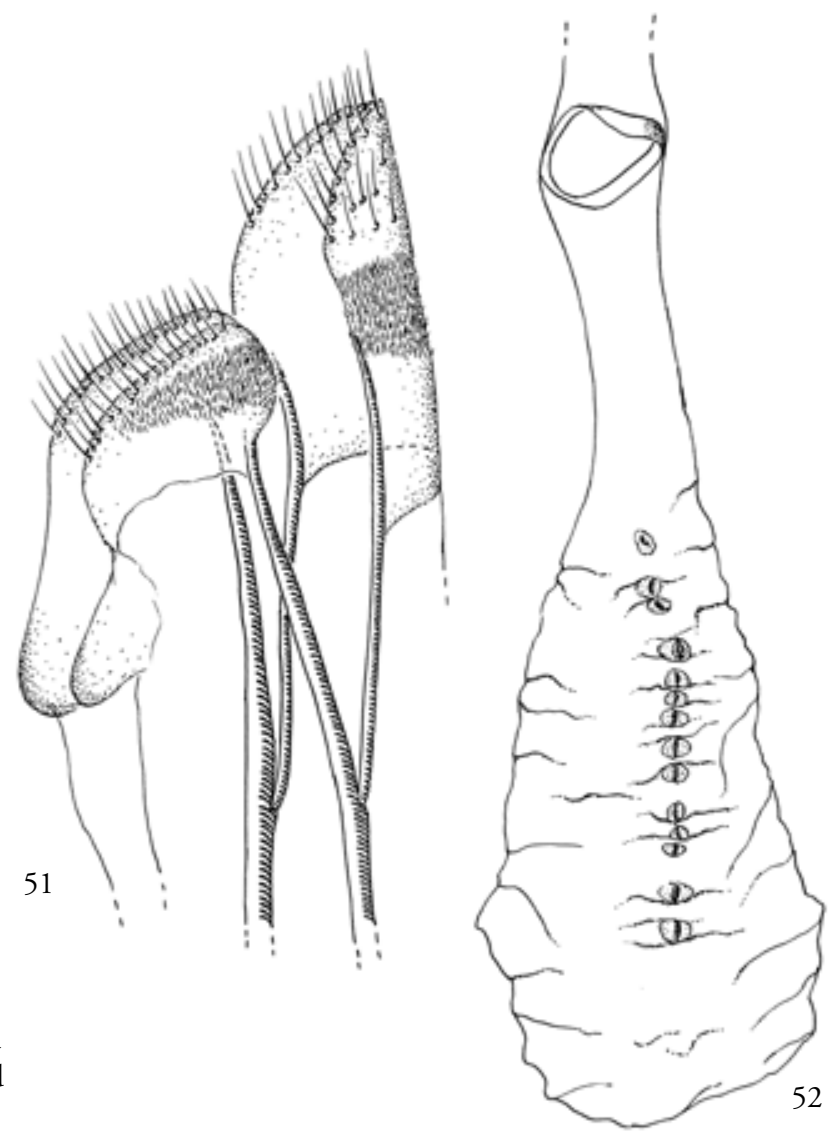

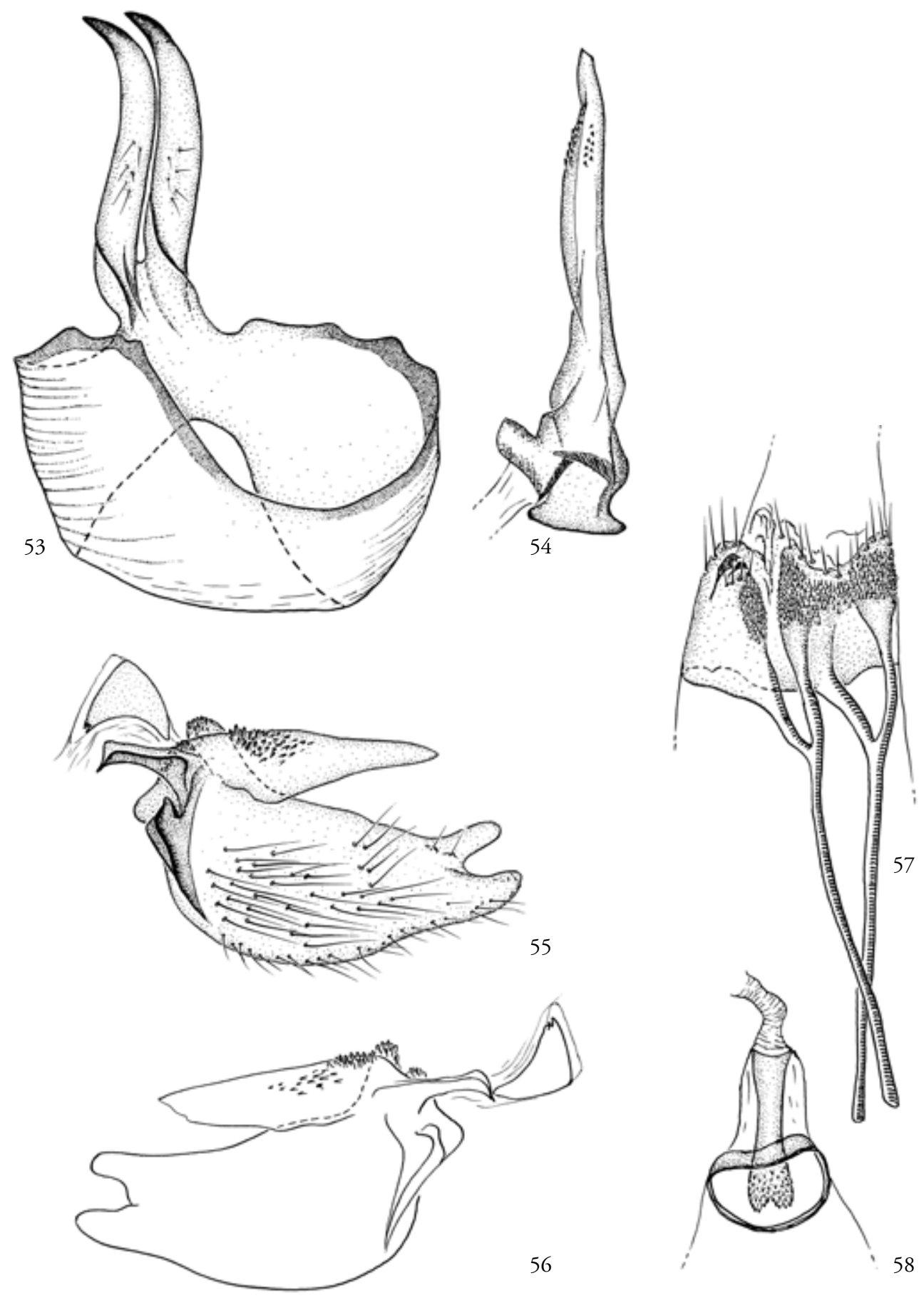

Fig. 53-58: Edosa parva (ơ: 53 - Uncus-Tegumen; 54 - Phallus; 55-56 - Valven (leicht asymmetrisch); 우 57 - VIII. Segment; 58 - Sklerotisierung im Ductus bursae). 


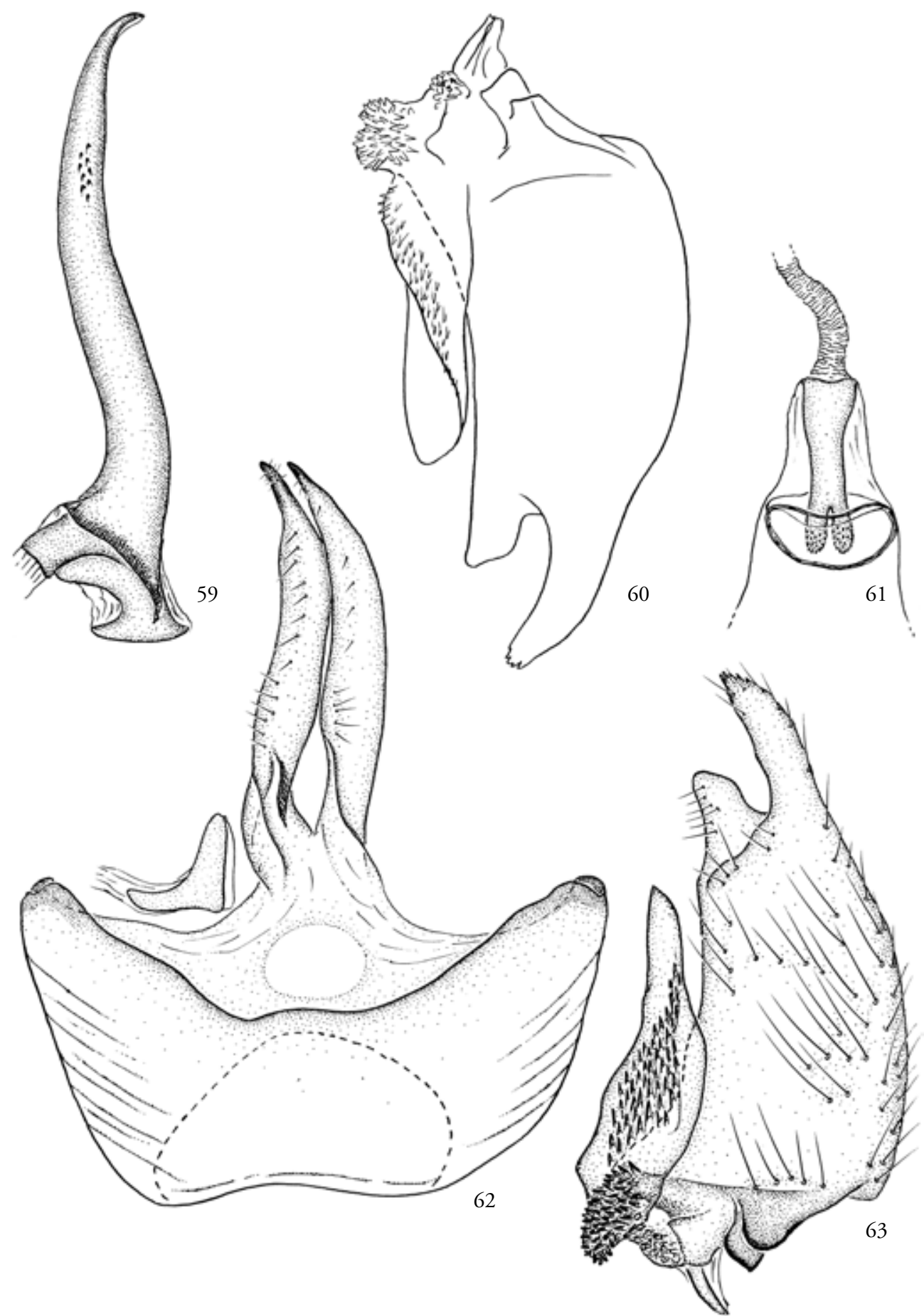

Fig. 59-63: Edosa magna (ơ: 59 - Phallus; 60, 63 - Valven (leicht asymmetrisch); 62 - Uncus-Tegumen; ๆ: 61 - Sklerotisierung im Ductus bursae). 

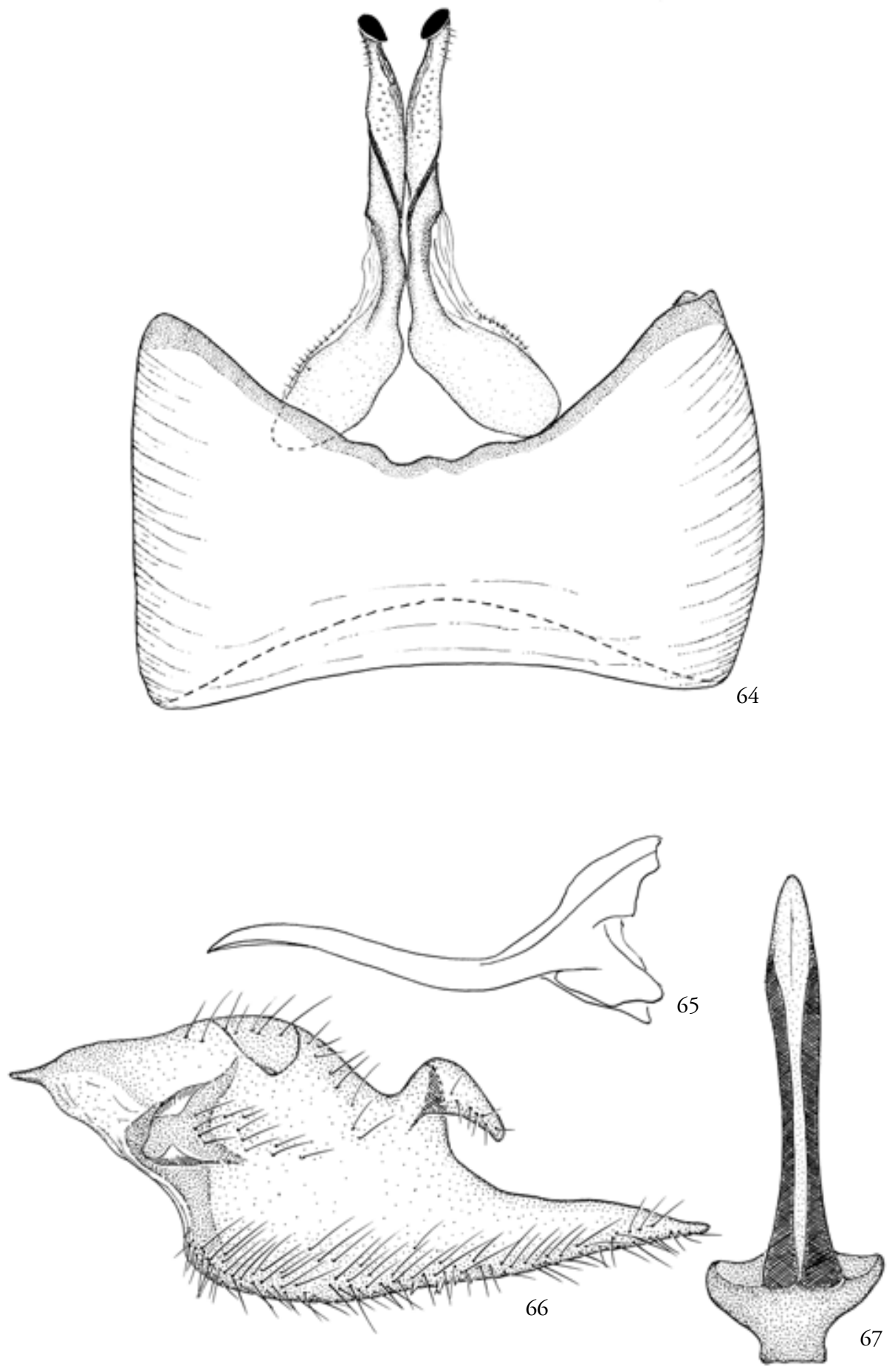

Fig. 64-67: Edosa fastigata, ơ (64 - Uncus-Tegumen; 66 - Valve; 65, 67 - Phallus lateral und ventral). 

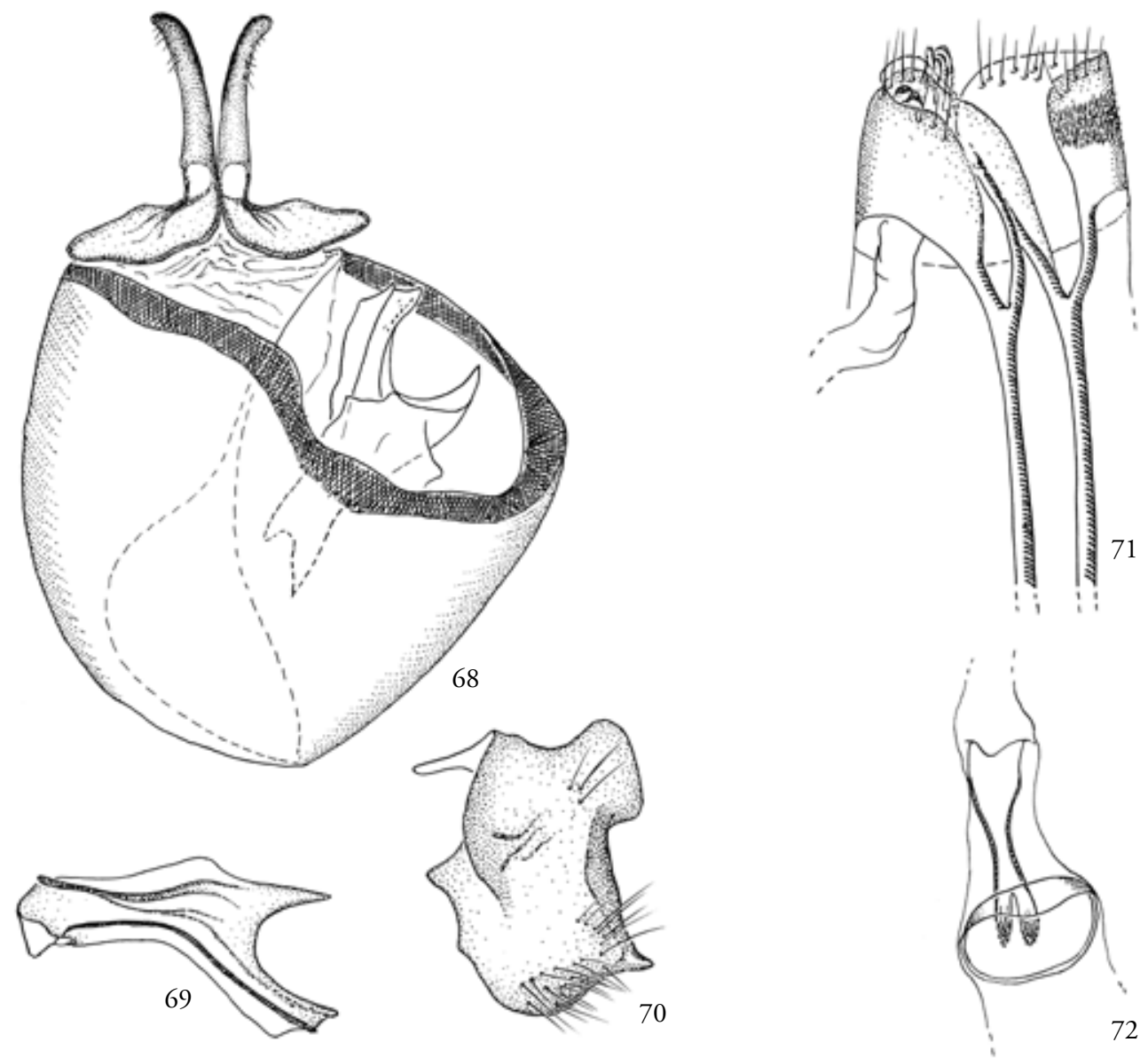

Fig. 68-72: Edosa rapticola (o : 68 - Uncus-Tegumen mit Phallus; - Phallus, lateral; 70 - Valve; 69 - + : 71 - VIII. Segment; 72 - Sklerotisierung im Ductus bursae).

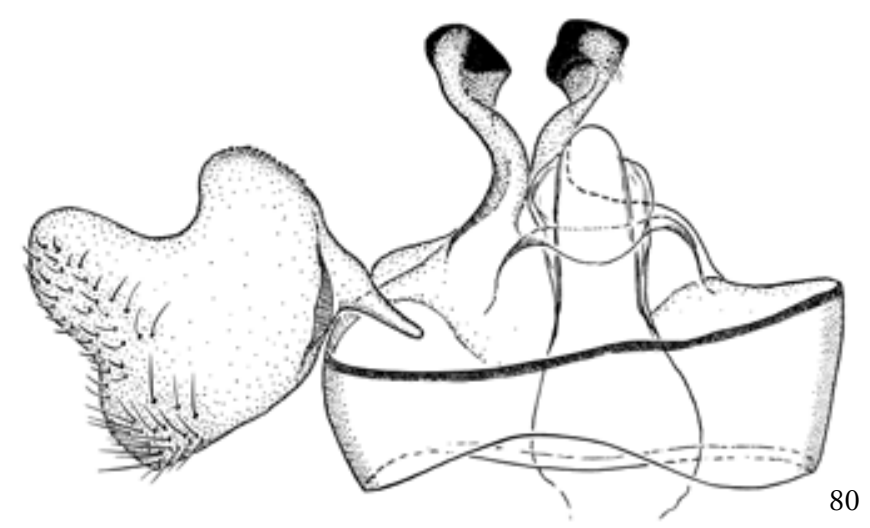

Fig. 80: Edosa clavifera, ơ. 

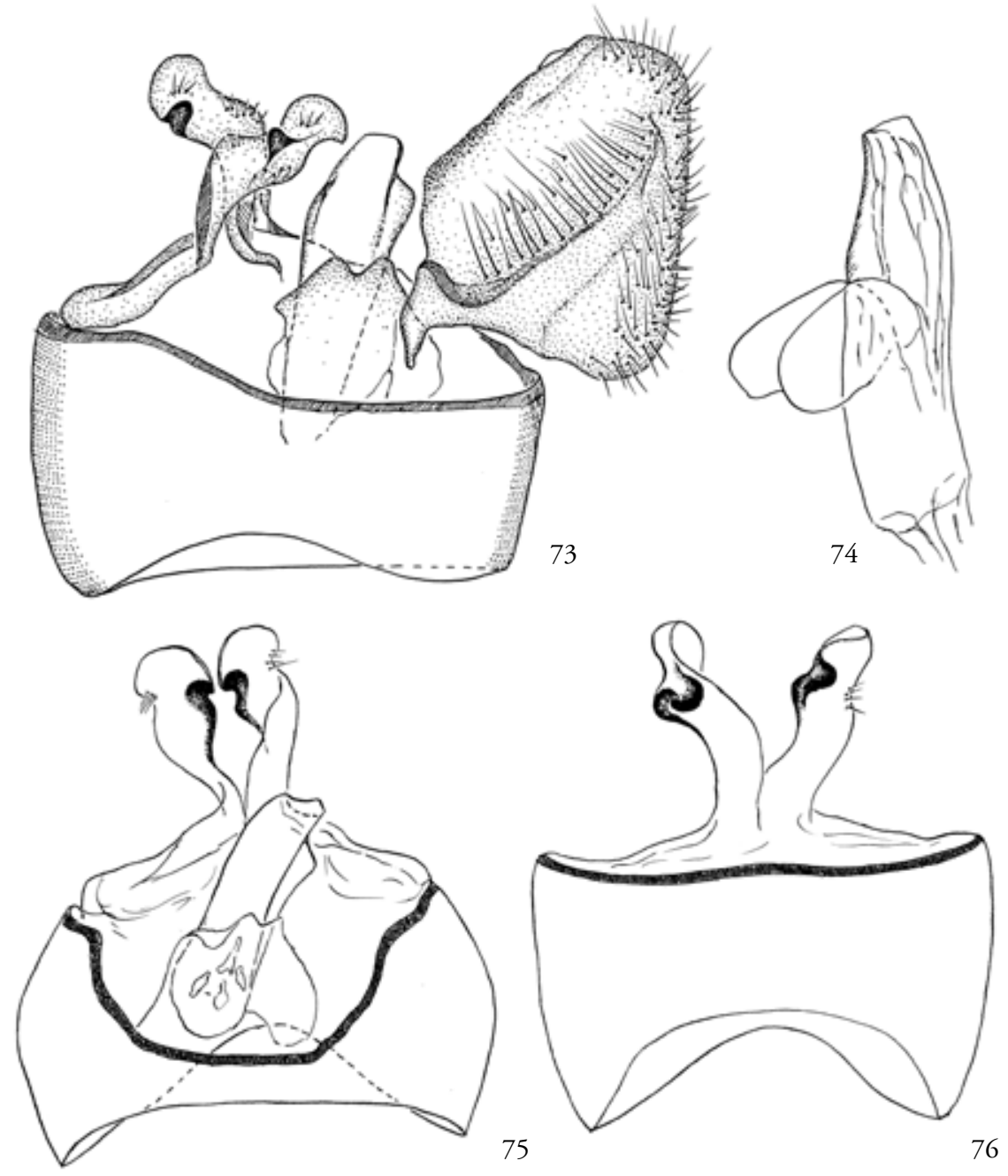

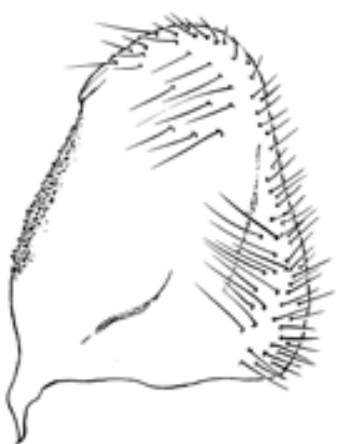

77

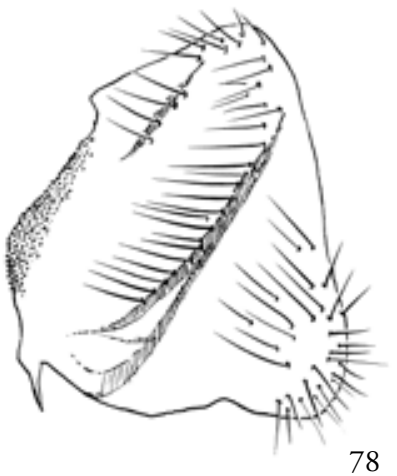

78

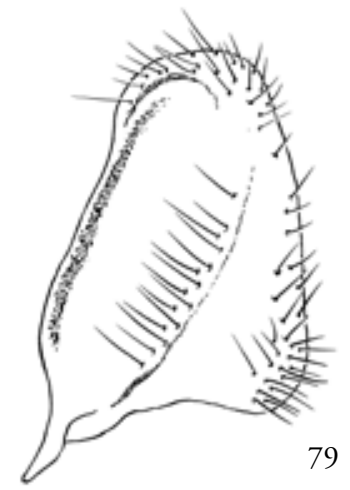

Fig. 73-79: Edosa subochraceella, ơ (73 - Genital, linke Valve entfernt; 74 - Phallus mit Anellus, lateral; 75-76 - Variabilität der Socii; 77-79 - Variabilität der Valven). 


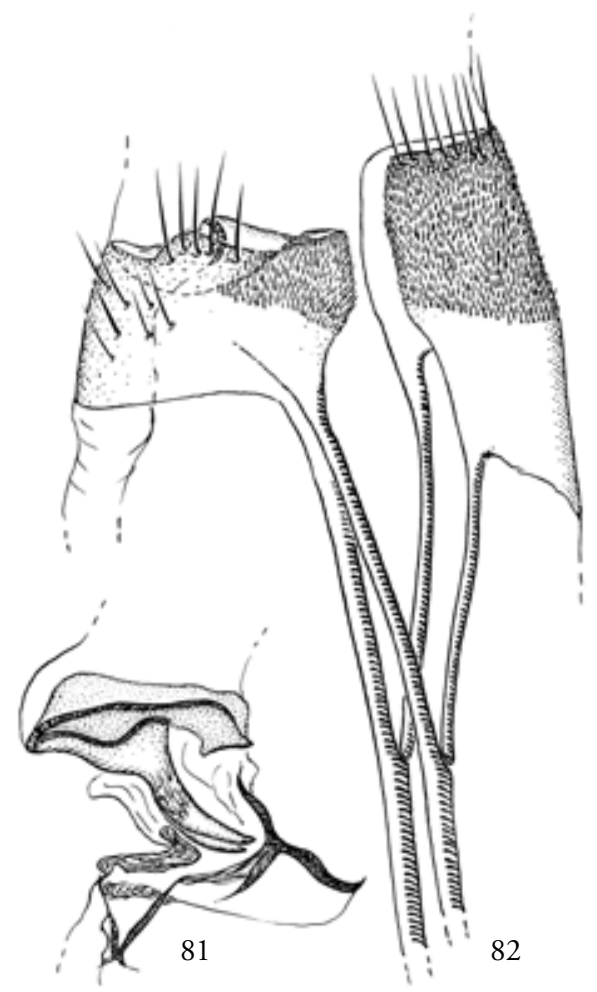

Fig. 81-82: Edosa clavifera, † (82 - VIII. Segment; 81 - Sklerotisierung im Ductus bursae)

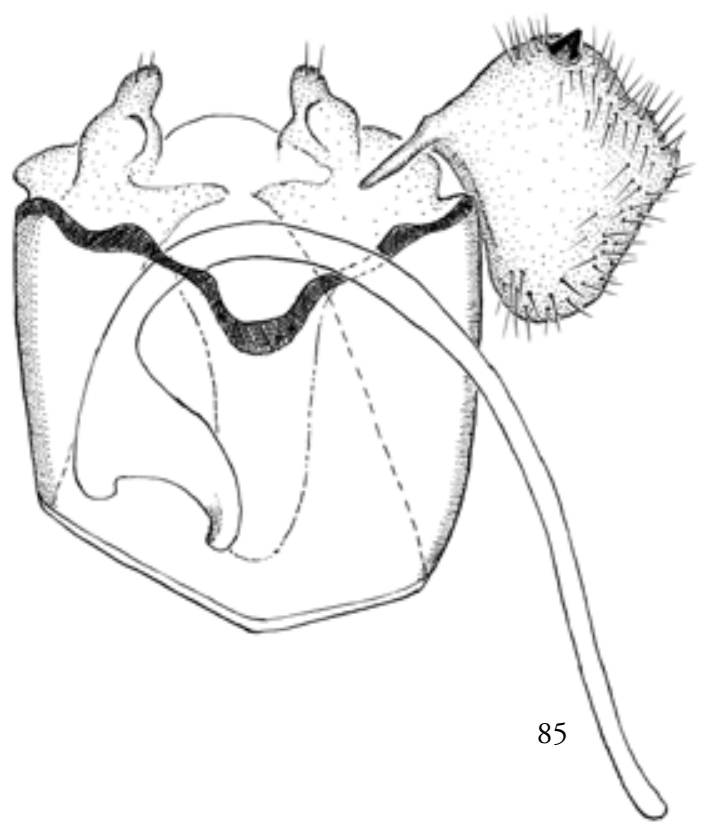

Fig. 85: Edosa hackeri, o.
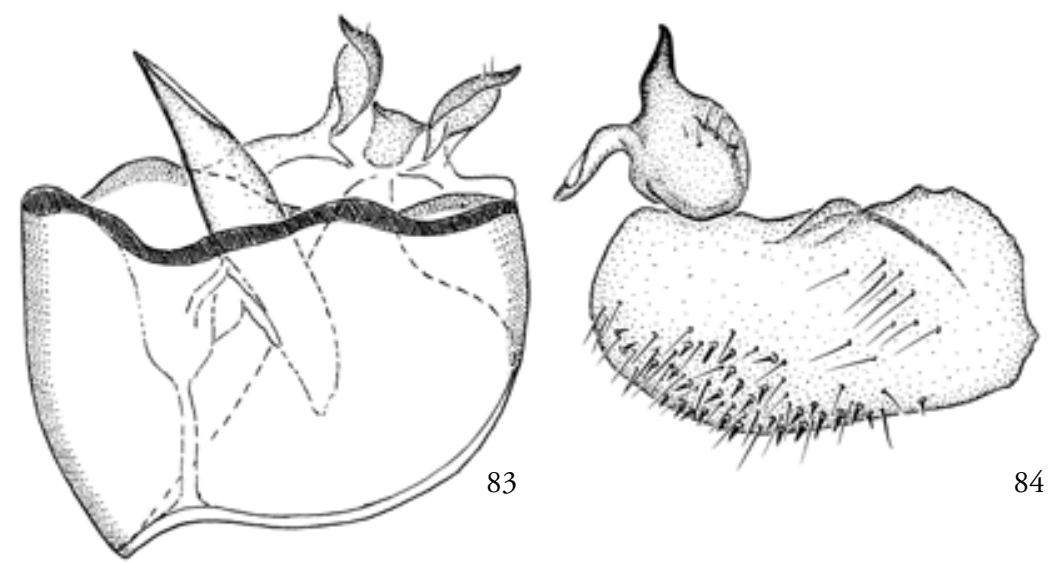

Fig. 83-84: Edosa dierli, ơ (83 - Genital ohne Valven; 84 - Valve). 


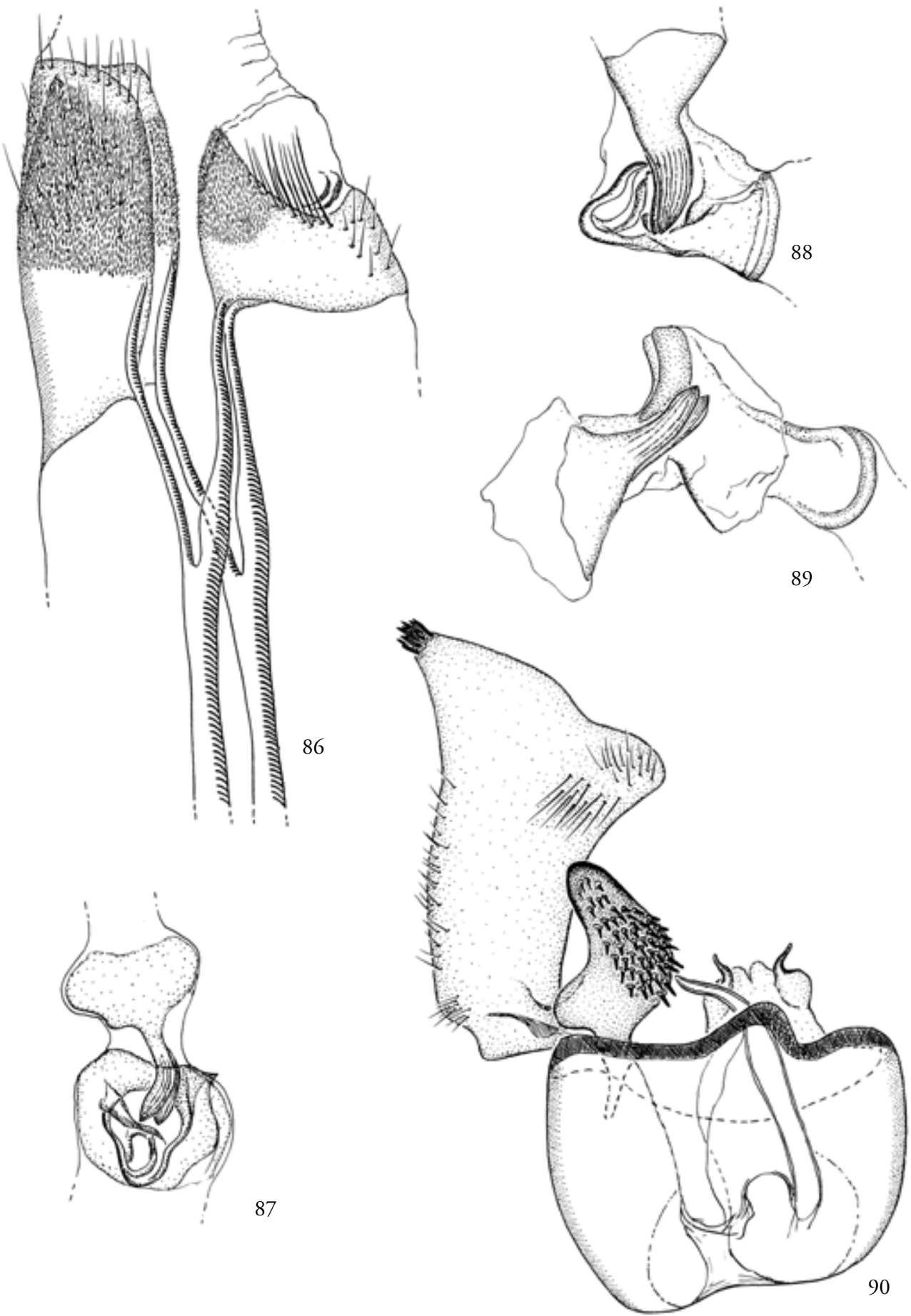

Fig. 86-89: Edosa opsigona, ㅇ (86 - VIII. Segment; 87-89 - Sklerotisierung im Ductus bursae: Variabilität) Fig. 90: Edosa spinosa, ơ (eine Valve entfernt). 

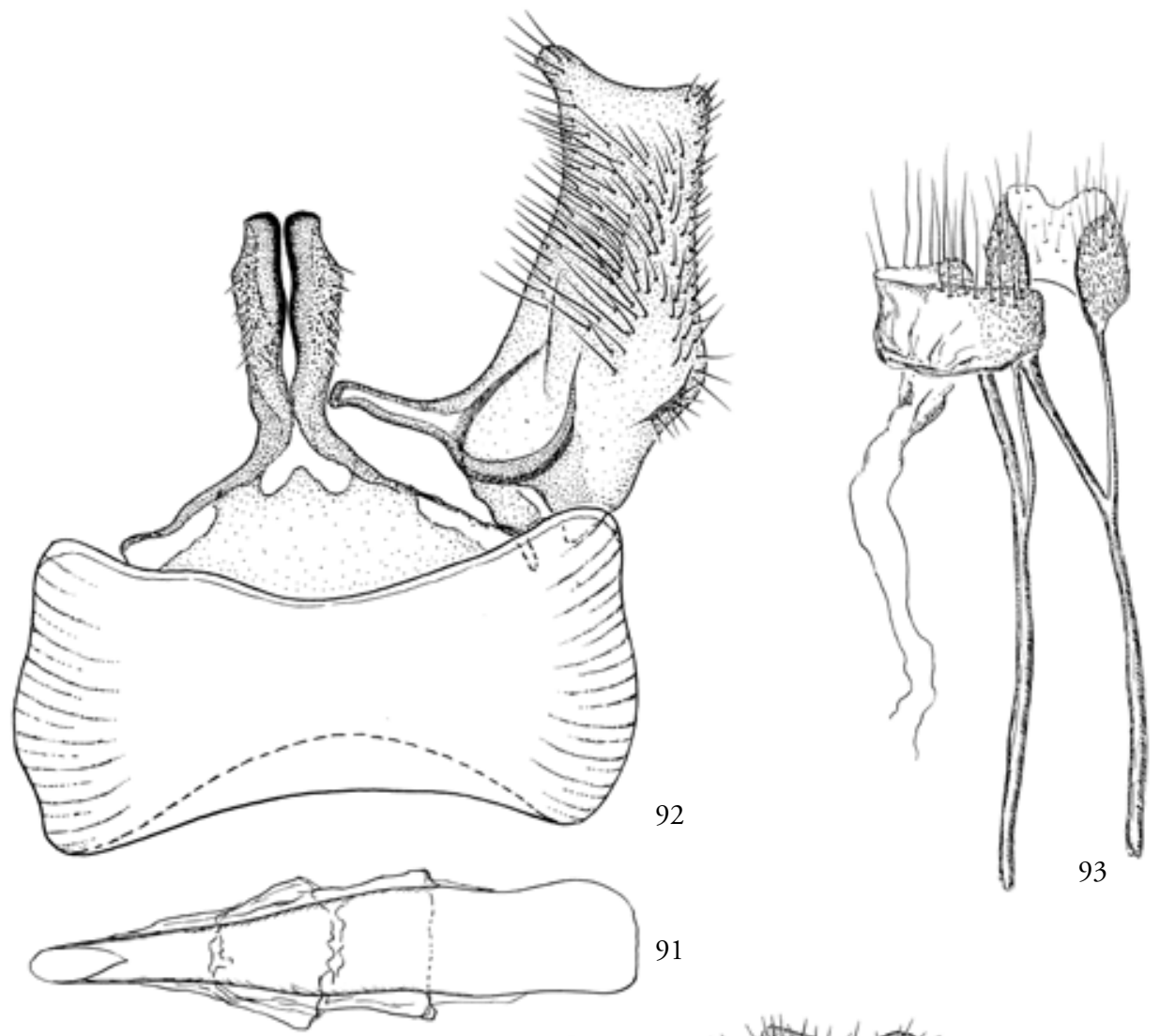

Fig. 91-92: Edosa fibigeri, ơ (91 - Uncus-Tegumen, eine Valve; 92 - Phallus).

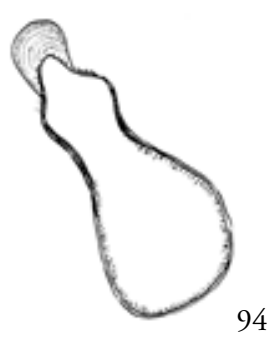

Fig. 93-95: Edosa nestoria, ㅇ (93 - VIII. Segment; 94 Signum; 95 - Signumrand, stärker vergrößert). Fig. 96: Perissomastix (Aphrodoxa) peterseni, ㅇ. .

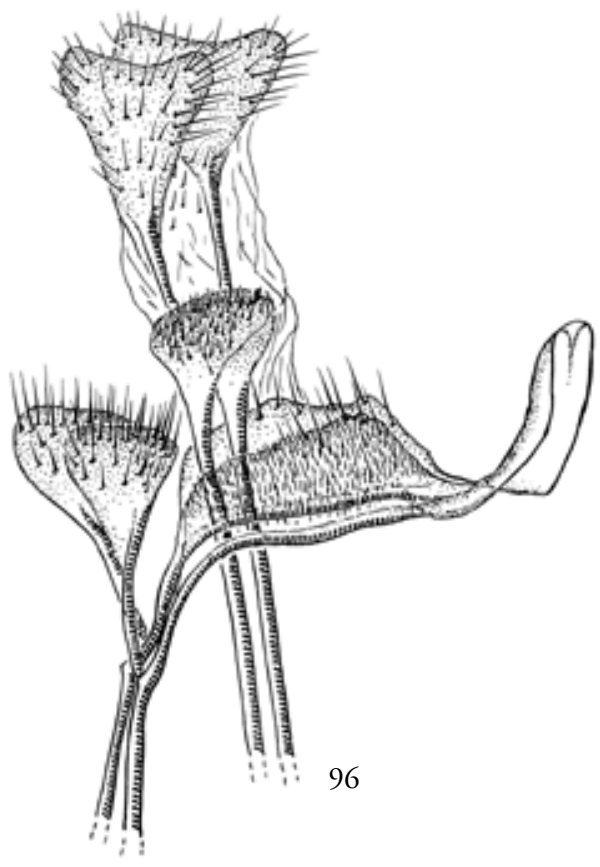



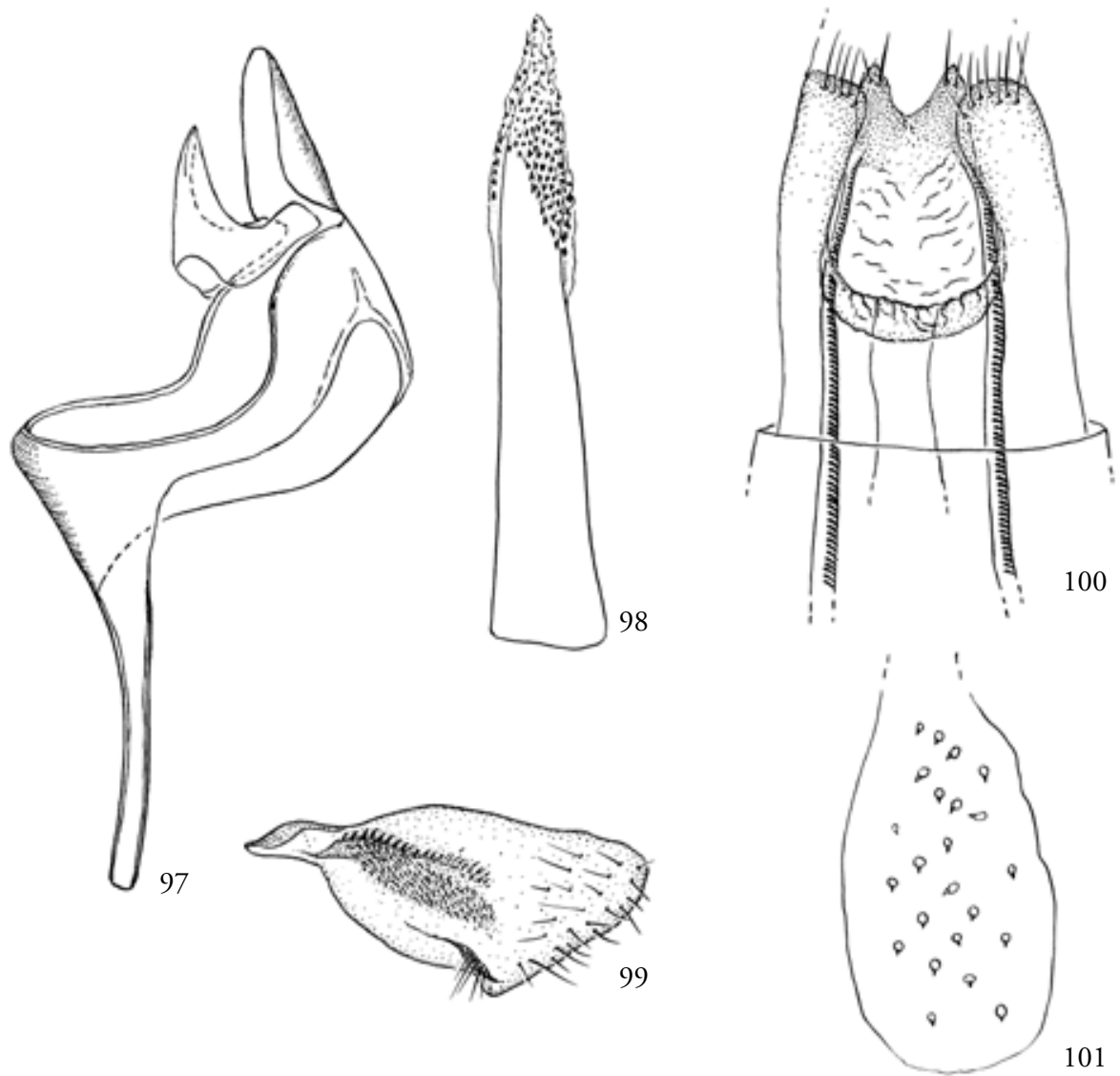

Fig. 97-101: Tinea nepalica ( $0^{*}: 97$ - Uncus-Tegumen-Vinculum; 98 - Valve; 99 - Phallus; 9 : 100 - VIII. Segment, ventral; 101 - Corpus bursae). 

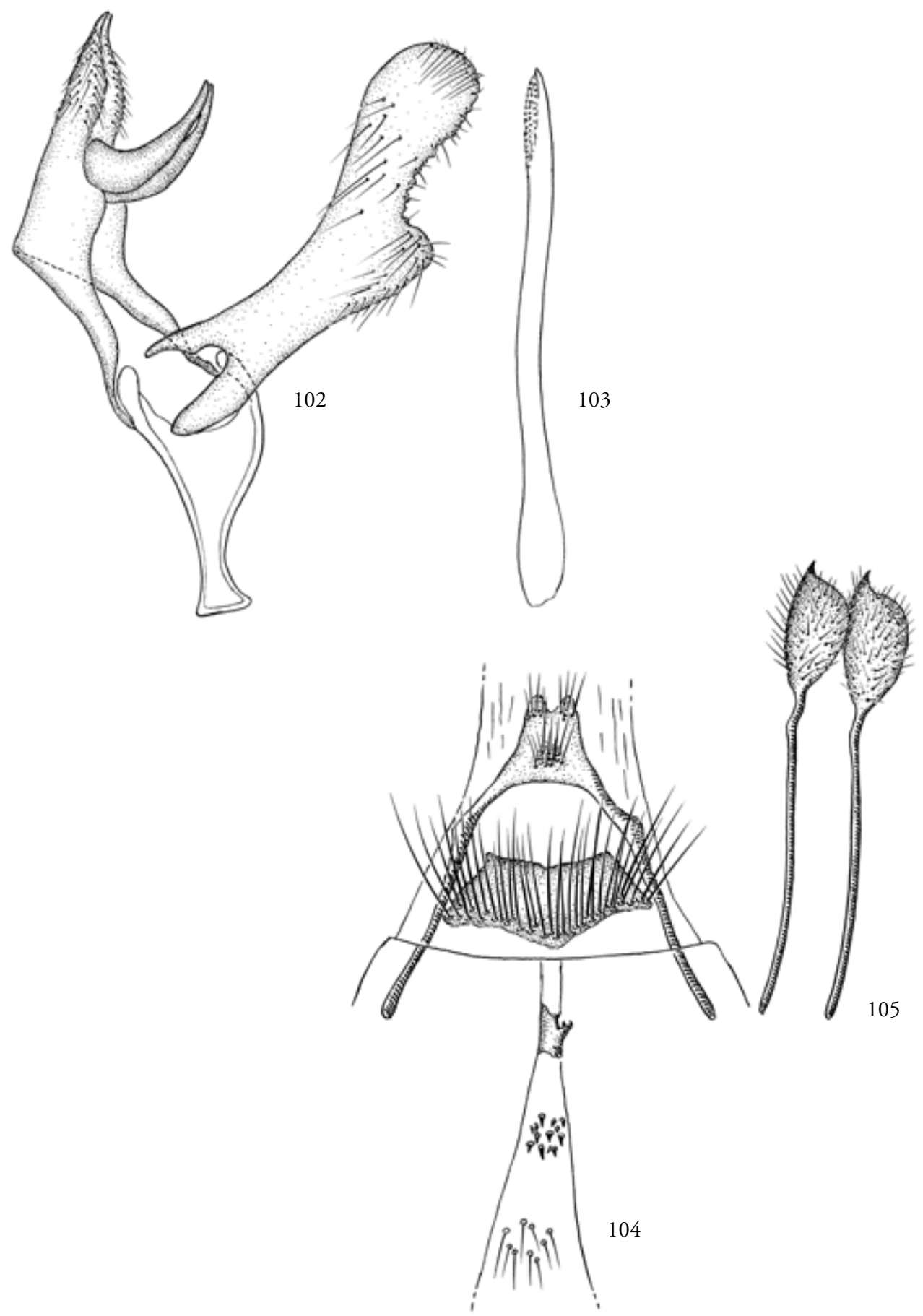

Fig. 102-105: Crypsithyris arenbergerarum ( $0^{*}: 102$ - Genital, eine Valve entfernt, ohne Phallus; 103 Phallus; ㅇ: 104 - VIII. Segment mit Ductus bursae; 105 - Analpapillen). 


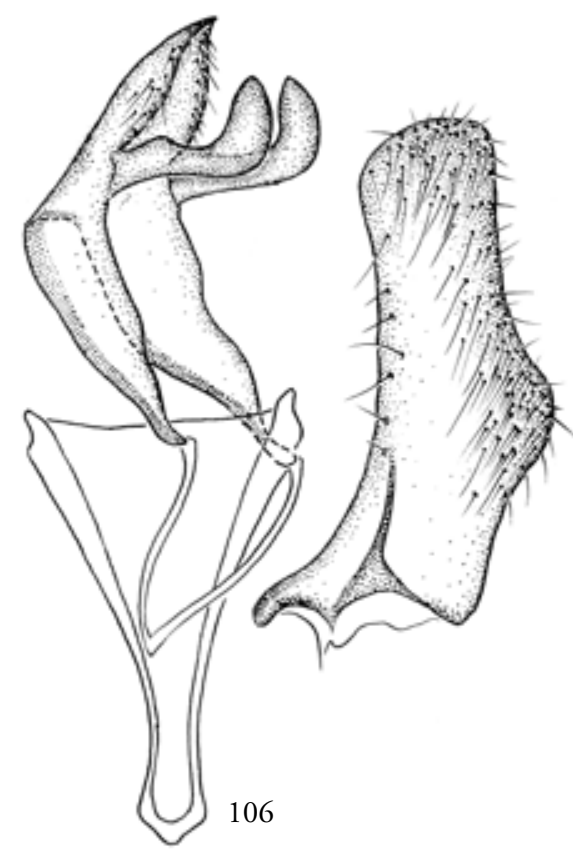

107
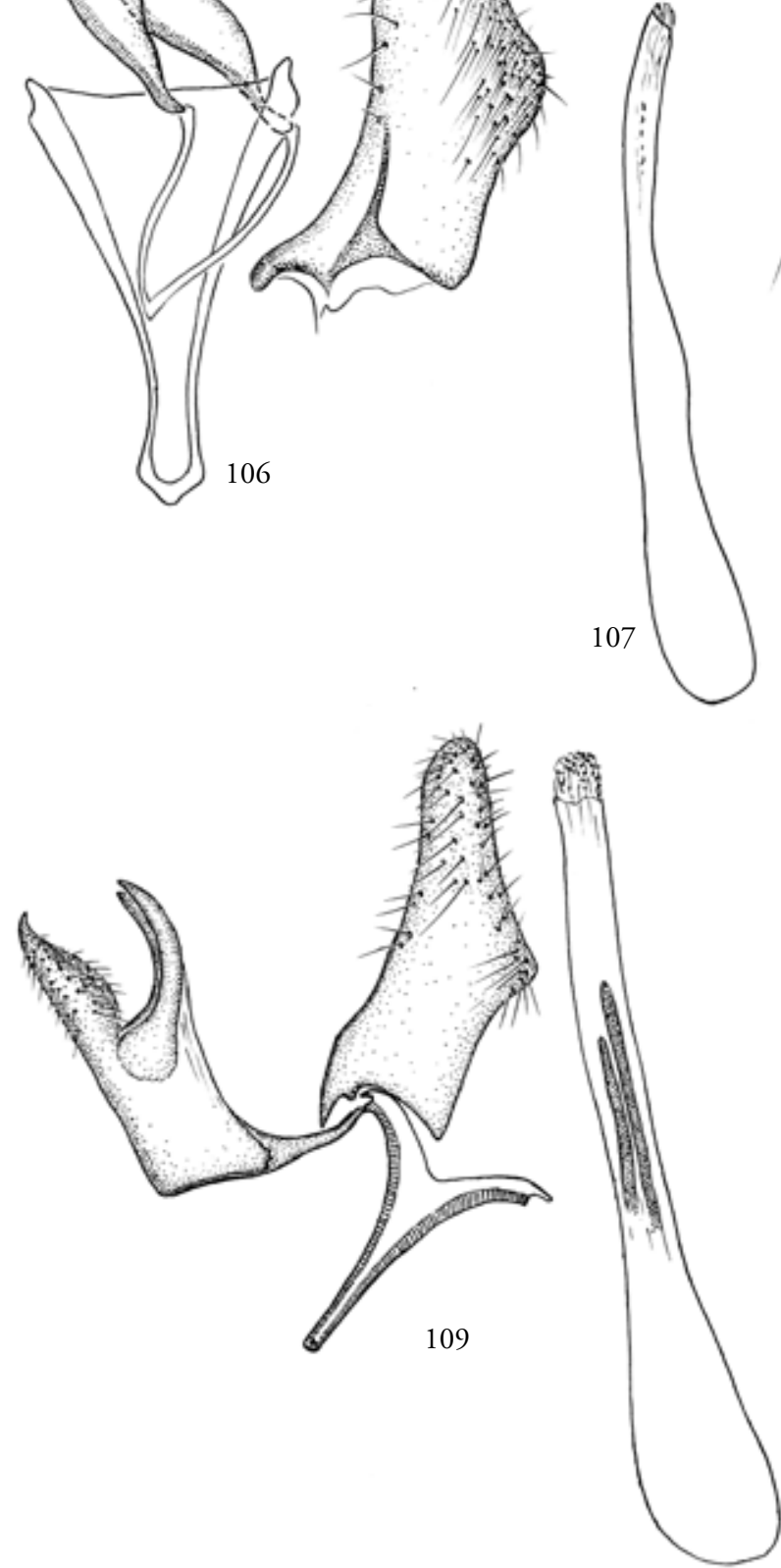

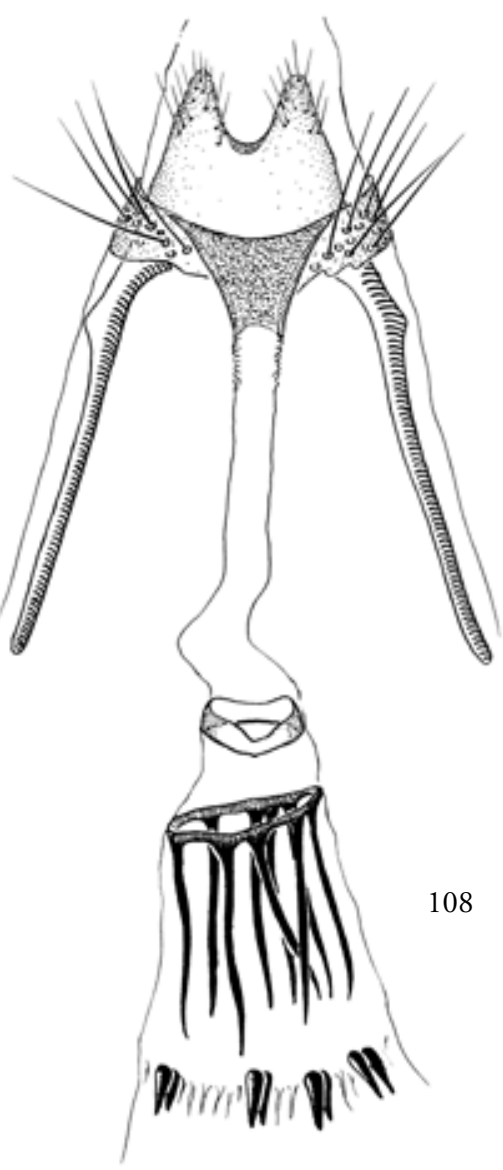

Fig. 106-107: Crypsithyris nepalicola, ơ (106 - Genital, eine Valve entfernt, ohne Phallus; 107 - Phallus).

Fig. 108: Crypsithyris nepalicola, of .

Fig. 109: Crypsithyris cornuta, o (eine Valve entfernt, Phallus separiert). 